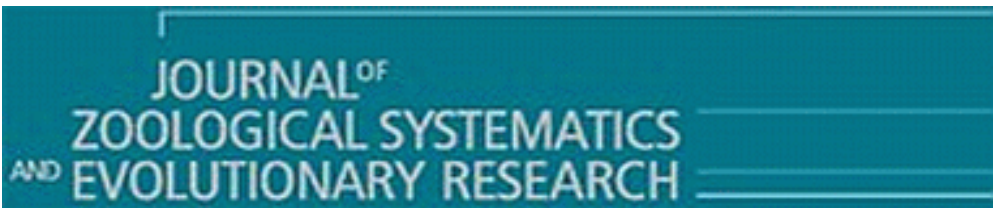

\title{
Comparative phylogeography and asymmetric hybridization between cryptic bat species
}

\begin{tabular}{|c|c|}
\hline Journal: & Journal of Zoological Systematics and Evolutionary Research \\
\hline Manuscript ID & JZS.201900005.R2 \\
\hline Wiley - Manuscript type: & Original Article \\
\hline $\begin{array}{r}\text { Date Submitted by the } \\
\text { Author: }\end{array}$ & $\mathrm{n} / \mathrm{a}$ \\
\hline Complete List of Authors: & $\begin{array}{l}\text { Centeno-Cuadros, Alejandro; Universidad de Cádiz Facultad de Ciencias } \\
\text { del Mar y Ambientales, Biomedicina, Biotecnología y Salud Pública } \\
\text { Razgour, Orly; University of Southampton Centre for Biological Sciences, } \\
\text { Centre for Biological Sciences } \\
\text { García-Mudarra, Juan Luís; Estacion Biologica de Donana CSIC, Ecología } \\
\text { Evolutiva } \\
\text { Mingo-Casas, Patricia; Instituto de Salud Carlos III Campus de } \\
\text { Majadahonda, Instituto de Salud Carlos III } \\
\text { Sandonís, Virginia; Instituto de Salud Carlos III Campus de } \\
\text { Majadahonda, Instituto de Salud Carlos III } \\
\text { Redondo, Adrián; Estacion Biologica de Donana CSIC, Ecología Evolutiva } \\
\text { Ibáñez, Carlos; Estacion Biologica de Donana CSIC, Ecología Evolutiva } \\
\text { de Paz, Óscar; Universidad de Alcala de Henares, Ciencias de la Vida } \\
\text { Martinez-Alós, Susana; Universidad de Alcala de Henares, Ciencias de la } \\
\text { Vida } \\
\text { Pérez Suarez, Gonzalo; Universidad de Alcala de Henares, Ciencias de la } \\
\text { Vida } \\
\text { Echevarría, Juan; Instituto de Salud Carlos III Campus de Majadahonda, } \\
\text { Instituto de Salud Carlos III; CIBER de Epidemiología y Salud Pública, } \\
\text { CIBERESP } \\
\text { Juste, Javier; Estacion Biologica de Donana CSIC, Ecología Evolutiva }\end{array}$ \\
\hline Keywords: & $\begin{array}{l}\text { Eptesicus, isabellinus, serotinus, Approximate Bayesian Computation, } \\
\text { hybrids }\end{array}$ \\
\hline Abstract: & $\begin{array}{l}\text { Cryptic speciation and hybridization are two key processes that affect the } \\
\text { origin and maintenance of biodiversity and our ability to understand and } \\
\text { estimate it. To determine how these two processes interact, we studied } \\
\text { allopatric and sympatric colonies of two cryptic bat species (Eptesicus } \\
\text { serotinus and E. isabellinus) with parapatric distribution in the Iberian } \\
\text { Peninsula. These species are the main reservoir for the most commonly } \\
\text { rabies virus found in bats in Europe: the European Bat Lyssavirus type } 1 \\
\text { (EBLV-1). We used mtDNA and nuclear microsatellite markers to confirm } \\
\text { the taxonomic status of both species and to show a more pronounced } \\
\text { and geographically-based genetic structure in E. isabellinus than in its } \\
\text { sibling E. serotinus. Using Approximate Bayesian Computation (ABC) we } \\
\text { inferred rapid range expansion in both species after the Last Glacial } \\
\text { Maximum until reaching their present distributions. ABC analysis also } \\
\text { supported interspecific differences in genetic diversity and structure, }\end{array}$ \\
\hline
\end{tabular}



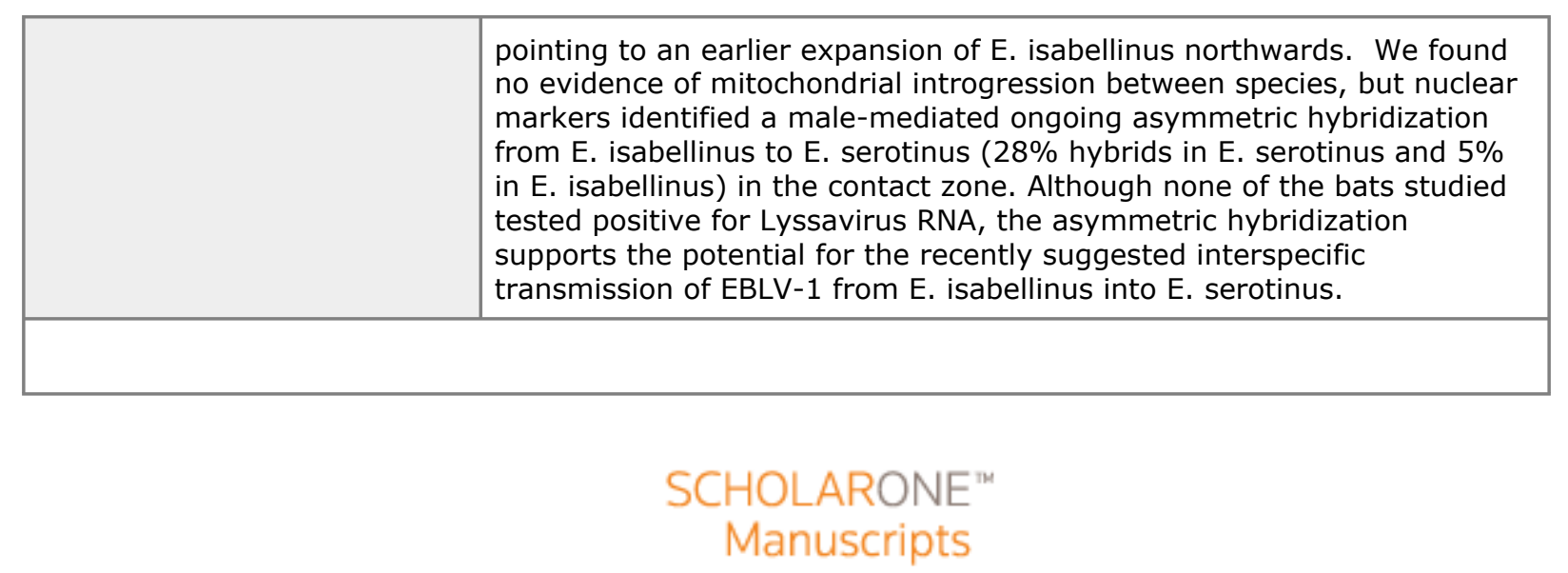


\section{Original article}

\section{COMPARATIVE PHYLOGEOGRAPHY AND ASYMMETRIC HYBRIDIZATION} BETWEEN CRYPTIC BAT SPECIES

Running title: Hybridization between cryptic bats

Alejandro Centeno-Cuadros ${ }^{\mathrm{a}^{*}}$, Orly Razgour ${ }^{\mathrm{b}}$, Juan Luís García-Mudarra ${ }^{\mathrm{c}}$, Patricia MingoCasas $^{\mathrm{d}}$, Virginia Sandonís ${ }^{\mathrm{d}}$, Adrián Redondo ${ }^{\mathrm{c}}$, Carlos Ibáñez ${ }^{\mathrm{c}}$, Oscar de Paz ${ }^{\mathrm{e}}$, Susana Martinez-Alós ${ }^{\mathrm{e}}$, Gonzalo Pérez Suarez ${ }^{\mathrm{e}}$, Juan Emilio Echevarría ${ }^{\mathrm{d}, \mathrm{f}}$ and Javier Juste* c,f a Área de Genética, Facultad de Ciencias del Mar y Ambientales, Universidad de Cádiz, Cádiz, Spain. ${ }^{b}$ Biological Sciences, University of Southampton, Southampton, United Kingdom. ${ }^{\mathrm{c}}$ Departmento de Ecología Evolutiva. Estación Biológica de Doñana (CSIC). C/ Américo Vespucio 26. 41092. Sevilla, Spain. ${ }^{d}$ Instituto de Salud Carlos III, Majadahonda, Madrid, Spain. e Departamento de Ciencias de la Vida, Facultad de Ciencias, Universidad de Alcalá, ES_28805 Alcalá de Henares, Madrid, Spain. ${ }^{\mathrm{f}}$ CIBER de Epidemiología y Salud Pública. CIBERESP, Spain

* These authors should be considered joint first author

Corresponding author: Javier Juste. Estación Biológica de Doñana (CSIC). Avda Américo Vespucio 26. 41092 Sevilla (Spain). Phone + 34 954466700. Fax + 34 954621125. Email: juste@ebd.csic.es.

\section{Authors' email addresses}

A.C-C. alejandro.centeno@uca.es. O.R.: orly.razgour@gmail.com. J.L.G-M.: juanele@ebd.csic.es. P.M-C.: linkinpatri@gmail.com. V.S.: vsandonism@externos.isciii.es.

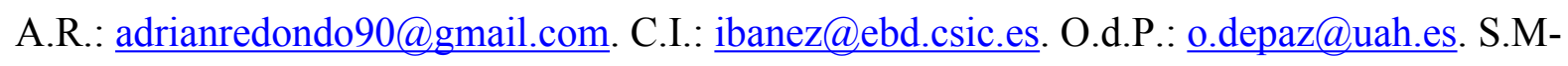
A.: susana.martinez@,uah.es. G.P-S.: gonzalo.perez@uah.es. J.E.E.: jeecheva@,isciii.es. J.J.: juste@ebd.csic.es.

Keywords: Eptesicus; isabellinus; serotinus; Approximate Bayesian Computation; hybrids. 


\section{ABSTRACT}

Cryptic speciation and hybridization are two key processes that affect the origin and maintenance of biodiversity and our ability to understand and estimate it. To determine how these two processes interact, we studied allopatric and sympatric colonies of two cryptic bat species (Eptesicus serotinus and E. isabellinus) with parapatric distribution in the Iberian Peninsula. These species are the main reservoir for the most commonly rabies virus found in bats in Europe: the European Bat Lyssavirus type 1 (EBLV-1). We used mtDNA and nuclear microsatellite markers to confirm the taxonomic status of both species and to show a more pronounced and geographically-based genetic structure in E. isabellinus than in its sibling $E$. serotinus. Using Approximate Bayesian Computation (ABC) we inferred rapid range expansion in both species after the Last Glacial Maximum until reaching their present distributions. ABC analysis also supported interspecific differences in genetic diversity and structure, pointing to an earlier expansion of E. isabellinus northwards. We found no evidence of mitochondrial introgression between species, but nuclear markers identified a male-mediated ongoing asymmetric hybridization from E. isabellinus to E. serotinus (28\% hybrids in E. serotinus and 5\% in E. isabellinus) in the contact zone. Although none of the bats studied tested positive for Lyssavirus RNA, the asymmetric hybridization supports the potential for the recently suggested interspecific transmission of EBLV-1 from E. isabellinus into E. serotinus. 


\section{INTRODUCTION}

Given rising threats from anthropogenic climate and land-use changes, it has never been more important to understand biodiversity (Leadley, 2010) and the extinction and speciation processes that drive its origin and maintenance (Hewitt, 2001). Cryptic speciation, the process of evolutionary divergence in the absence of morphological differentiation, has been described in a variety of organisms and ecosystems, and has important implications not only for biodiversity estimates but also for habitat conservation, wildlife management (Bickford et al., 2007), pest control and epidemiology (de Vienne et al., 2013; Doña et al., 2017). Nevertheless, the genetic and ecological interactions between sibling species are not well understood (Struck et al., 2017), particularly when they are found in sympatry. A useful approach is the analysis and comparison of the recent phylogeographic history of the distinct lineages and inspection of their particular responses to environmental/climatic changes (e.g. glacial cycles) by analyzing how expansion/retraction events associated with these climatic changes shaped their genetic make-up (Carstens \& Richards, 2007; Richards, Carstens, \& Lacey Knowles, 2007). On the other hand, hybridization (defined as the admixture of evolutionary distinct lineages) is also a fundamental evolutionary process, commonly described in plants and animals, which is important in generating biodiversity (e.g. speciation) and its conservation (Mallet, 2005). The exchange of genetic material along secondary contact zones particularly during lineage expansions is well documented and often results in increased genetic diversity and adaptability of the new gene pools (Barton \& Hewitt, 1985). This contact of formerly isolated gene pools can bring about genomic introgression (Currat et al. 2008) or hybrid speciation (Canestrelli et al., 2016; Mallet, 2007), both recognized as major evolutionary drivers (reviewed in Abbott et al. 2013).

Since cryptic speciation and hybridization contribute substantially to the origin and spatial distribution of biodiversity, the ecological and evolutionary consequences of these 
processes have been widely addressed (Battey \& Klicka, 2017; Martinsson \& Erséus, 2017; Seehausen, Takimoto, Roy, \& Jokela, 2008; Soltis \& Soltis, 2009). However, their interaction (hybridization between cryptic species) has received little attention. We can expect that both processes are correlated, and that hybridization is more successful between cryptic sibling species (genetically distinct but morphologically identical species) due to a higher genetic compatibility between closely related lineages, as has been found for some birds (Mallet, 2005) and plants (Maguilla \& Escudero, 2016) under natural conditions. Successful hybridization between differentiated lineages is also expected to be enhanced when these cryptic lineages share similar ecological requirements and sympatric (or parapatric) distributions.

The application of molecular techniques to species identification and hybridization studies has greatly contributed to understanding these biological processes (Allendorf et al., 2001; Frankel, 1974; Fitzpatrick et al., 2012). In fact, the molecular review of traditional taxonomy has recognized often distinct evolutionary lineages within morphologically identical entities (i.e. cryptic species) unveiling important hidden diversity (Pfenninger \& Schwenk, 2007). Codominant markers such as microsatellites are useful for detecting hybrids (e.g. Randi 2008; Fitzpatrick 2012), allowing the identification of groups and individual assignments through clustering algorithms (Bohling, Adams, \& Waits, 2013; Vähä \& Primmer, 2006). Multi-marker approaches (for example, those combing microsatellites with mitochondrial DNA [mtDNA] sequences) in particular, provide powerful tools to address phylogeographic questions and to reconstruct intra- and inter-specific differentiation processes (Dool et al., 2013; Mallet, 2005; Mallet, Besansky, \& Hahn, 2016; Mitchell, Muehlbauer, \& Freedberg, 2016). In fact, the distinct genetic information provided by each marker, together with the recent application of Approximate Bayesian Computation (ABC) approaches (Beaumont, Zhang, \& Balding, 2002) to statistically compare alternative 
evolutionary history scenarios, are improving our understanding of the evolutionary processes behind the origin and geographical patterns of present biodiversity.

Bats are a particularly suitable group for studying cryptic speciation, hybridization and their interactions due to their high proportion of cryptic species and their rich and complex social and interspecific relationships (Altringham, 2011). Molecular studies have unveiled an unexpectedly high proportion of cryptic diversity within the group, and the majority of the 191 new bat species recognized from 1992 (Koopman, 1993) to 2005 (Simmons, 2005) were described within already known morphological complexes. In the Iberian Peninsula (hereafter Iberia), new cryptic lineages are found in up to $20 \%$ of the traditional morphologicallydefined species (Ibáñez, García-Mudarra, Ruedi, Stadelmann, \& Juste, 2006). On the other hand, hybridization, and particularly mtDNA introgression, has been reported in bats across families and habitats worldwide [e.g. Rhinolophus (X. G. Mao, Zhu, Zhang, \& Rossiter, 2010); Myotis (Berthier, Excoffier, \& Ruedi, 2006); Eptesicus (Artyushin et al. 2009); Uroderma (Hoffmann et al. 2003); Epomophorus (Nesi et al. 2011)]. The widespread mating behaviour of swarming, which involves the gathering of multi-species in a single site to breed, may facilitate -at least in some cases- this interspecific genetic exchange (Bogdanowicz et al. 2012).

In Iberia, the most divergent lineages were found within the serotine bat (Ibáñez et al., 2006). One lineage corresponded to Eptesicus serotinus (Schreber, 1774), a species common across Europe (C Moussy et al., 2015) and occupying the Northern half of Iberia, and another to E. isabellinus (Temminck, 1840), distributed along the southern half of Iberia and Northern Africa. A molecular revision of the genus Eptesicus confirmed the species status of the latter lineage (Javier Juste, Benda, Garcia-Mudarra, \& Ibáñez, 2013). Both species show different environmental preferences with a narrow and overlapping zone in central Iberia (Santos et al., 2014), which is the only area in which both species are in contact. This contact zone is acting 
as both the northernmost limit of the distribution for E. isabellinus and the southernmost limit of the distribution of the E. serotinus. Both species can only be distinguished morphologically by putative differences in their fur brown color (being generally darker in E. serotinus) and show wide overlap in all measurements (Juste et al., 2017). This bat complex is also considered the main natural reservoir of the European Bat Lyssavirus type-1 (EBLV-1), endemic to Europe and an important vector of rabies in humans and other mammals (P. Mingo-Casas et al., 2017). Eptesicus bats account for more than the 95\% of the rabid bats detected in Europe. Population structure of EBLV-1 is mostly driven by geographical factors, but each of the two Eptesicus bats seems to host distinct lineages of EBLV-1 in Iberia (Sonia Vázquez-Morón, Juste, Ibáñez, Berciano, \& Echevarría, 2011). The presence of a contact zone raises the possibility of viral exchanges with possible epidemiologic implications.

In this study, we sampled allopatric and sympatric colonies of the bats E. serotinus and E. isabellinus across Iberia, focusing on the contact zone of these sibling species. We aimed to i) reconstruct and compare the recent evolutionary histories of the two species, ii) assess the biological interactions between them, and iii) determine potential patterns of EBLV-1 transmission. We specifically tested the hypothesis of interspecific gene flow between these two cryptic bat species based on the combined information from mtDNA and nuclear microsatellite markers.

\section{MATERIAL AND METHODS}

\section{Sampling design}

We searched for Eptesicus bat colonies along the North-South gradient across Spain during spring (the reproductive season) from 1998 to 2013, mainly through inspecting potential refuges at dawn. Once the colony was identified, bats were mist-netted in one night and $2 \mathrm{~mm}$-diameter wing membrane biopsies were collected according to Worthington- 
Wilmer \& Barratt (1996) together with oropharyngeal swabs from each bat before they were released shortly after capture. Tissue samples were kept in $96 \%$ ethanol at $-20^{\circ} \mathrm{C}$ until processed in the lab and swabs stored in an RNA preservation lysis buffer (Casas, Powell, Klapper, \& Cleator, 1995) for later virus checking.

A total of 347 Eptesicus bats were captured and sampled from 19 breeding colonies across Iberia. Of these, 107 individuals from six maternity colonies were identified (based on their dark brown fur) in the field as presumably E. serotinus; two colonies (PCR and CTJ) were located in the contact zone, and the remaining four (CHA, TUD, CAN and UGA) were found throughout the northern non-overlapping area. All were stable maternity colonies with the exception of TUD, which was comprised of adult males only. The remaining 240 bats were identified as E. isabellinus, belonging to five breeding colonies within the contact zone (JAR, GAR, COR, SER and TOR) and eight colonies located in the allopatric area in Southern Iberia (AZN, ORG, ALC, HOR, BOQ, POS, USO and TRJ) (Figure 1, Tables 1 and 2). The taxonomic identification based on morphology was subsequently confirmed genetically using the numerous molecular diagnostic characters, particularly in the mtDNA, found between both lineages (Juste et al., 2013).

Prior to DNA extraction, the tissue was digested with proteinase K and total DNA was extracted following a standard phenol/chloroform protocol (Sambrook, Fritsch, Maniatis, Harbor, \& Slatkin, 1989). The colonies were considered sympatric if a colony of the sibling species was found within $50 \mathrm{~km}$ distance, given that both species are sedentary (Dietz, Nill, \& Helversen, 2009).

\section{Mitochondrial DNA analysis}

A section of the hyper-variable II region (HVII) of the mitochondrial control region (CR) was amplified in 107 E. serotinus and 240 E. isabellinus using the primers CSBC_F 
170 (Wilkinson \& Chapman, 1991) and H607_R (Wilmer, Moritz, Hall, \& Toop, 1994) annealing 171 in the conserved box $\mathrm{C}$ and the tRNA ${ }^{\mathrm{PHE}}$ gene, respectively. See Supporting Information 172 Table S1 for PCR conditions and primers. DNA sequences are uploaded to GenBank (accession numbers MH443793-MH444139).

Phylogenetic relationships between haplotypes were reconstructed with PAUP* $4.0 \mathrm{~b} 10$ (Swofford et al., 2001) using the Maximum Parsimony criterion (MP). Gaps were treated as "missing" and bootstrap support for the nodes was obtained after 2000 iterations. Mitochondrial DNA diversity was described based on the number of segregating sites (S), number of haplotypes $(\mathrm{h})$, haplotype diversity $(\mathrm{Hd})$, nucleotide diversity $(\pi)$ and average number of nucleotide differences $(\mathrm{k})$. All descriptors were estimated per species and colony using the software DnaSP 5.10 (Librado \& Rozas, 2009). To estimate genetic differentiation between populations we used Фst (Holsinger \& Weir, 2009) calculated in ARLEQUIN v.3.5.1.2 (Excoffier \& Lischer, 2010), as the analogue to Fst for microsatellites. Due to differences in the effective population sizes between mitochondrial (HVII) and nuclear (microsatellites) markers, we recalculated $\Phi_{\mathrm{ST}}$ based on Crochet (2000) $\left(\Phi_{\mathrm{ST}}\right)$ to compare it with $\mathrm{F}_{\mathrm{ST}}$-values (see below). Pairwise $\Phi_{\mathrm{ST}}$ distances estimated between colonies of both species were analyzed to evaluate the relative importance of isolation by distance (IBD). A Mantel test was performed through the Isolation by Distance Web Service (http://ibdws.sdsu.edu/ ibdws/) (Jensen, Bohonak, \& Kelley, 2005) using the log-transformed geographic distances between colonies obtained from GeoDataSource (http://www.geodatasource.com/distance-calculator). variability were evaluated in a hierarchical molecular analysis of variance (AMOVA) (L 
variation throughout the whole species range; 2) the genetic variability is mainly divided into colonies in allopatry and sympatry; and 3) the genetic variability of the species is divided into four groups based on geographic criteria (see below). A median-joining network of haplotypes was constructed for each species using Network 4.6.1.2 (Bandelt, Forster, \& Röhl, 1999). The resulting networks were simplified by cutting superfluous median vectors and pruning unnecessary links for E. isabellinus with the MP option of the software.

\section{Microsatellite genotyping and data analysis}

Individuals were genotyped using 12 microsatellites originally designed for the bats: Plecotus auritus (PAUR05, Burland et al. 1998), Myotis myotis (D15, Castella \& Ruedi 2000; NN8, Petri et al. 1997), Myotis bechsteinii (B22; Kerth et al. 2002), Eptesicus fuscus (EF1, EF14, EF15, EF20, EF4, EF6, Nyctalus noctula (P213), and Thyroptera tricolor (TT20, Vonhof et al. 2001). All indirectly labeled using a M13 extension (Schuelke, 2000). See Supporting Information Table S1 for PCR conditions. Microsatellites were selected to avoid linkage disequilibrium among loci, using GENEPOP on the web (Rousset, 2008), and null alleles by using the EM algorithm implemented in FREENA (Chapuis \& Estoup, 2007). Microsatellite datasets are available through the Mendeley data depository (DOI: http://dx.doi.org/10.17632/tpxc5dfs7v.1\#file-b0e6021e-88c3-417d-b612-62c44dc06cc7).

Hardy-Weinberg Equilibrium (HWE) was then tested per species, locus and population using Markov Chain Monte Carlo (MCMC) simulations in GENEPOP on the web (Rousset, 2008). Observed $\left(\mathrm{H}_{\mathrm{O}}\right)$ and (non-biased) expected $\left(\mathrm{H}_{\mathrm{E}}\right)$ heterozygosity were estimated using all loci per population with GENETIX 4.05.2 (Belkhir et al. 2004) and the inbreeding coefficient ( $\left.\mathrm{F}_{\mathrm{IS}}\right)$ using FSTAT v.2.9.3.2 (Goudet, 1995). Genetic structure was quantified with global $\mathrm{F}_{\mathrm{ST}}$ and $95 \%$ confidence intervals and population pairwise $\mathrm{F}_{\mathrm{ST}}$ values in GENETIX 4.05.2. 

\& Pritchard, 2007) both to estimate the genetic structure within each species separately and to determine whether there was admixture between them. The algorithm implemented in STRUCTURE infers the number of genetically differentiated groups $(\mathrm{K})$ and identifies pure and admixed individuals based on individual membership coefficients ( $q$-coefficients). The selection of $\mathrm{K}$ was based on the second-order rate of change of log probability of the data between successive values of K (Evanno, Regnaut, \& Goudet, 2005) as implemented in STRUCTURE HARVESTER (Earl \& von Holdt 2011). We applied this method using the admixture (independent allele frequency model) model and 10 replicates for each $\mathrm{K}$ (K ranging from 1 to 5) and ran simulations based on 100,000 MCMC iterations, collecting data every 100 steps. The first 10,000 steps were discarded as burn-in to estimate the convergence of the chains. CLUMPP v.1.1.2 (Jakobsson \& Rosenberg, 2007) was used to obtain the averaged individual $q$-coefficients. We also used a Discriminant Analysis of Principal Components (DAPC) (Thibaut Jombart et al., 2010), a method used to find group subdivision that maximizes differences between groups while minimizing variation within them. The DAPC were run using the Adegenet package in R (T. Jombart, 2008). We used the function find.clusters to run successive K-mean clustering with increasing number of clusters (max.n.clust=10) and applied the Bayesian Information Criterion (BIC) to select the model that best represents the number of groups.

\section{Identifying hybrids}

The program NEWHYBRIDS 1.1 beta (Anderson \& Thompson, 2002) was used to identify potential hybrids. Runs were performed using Jeffrey's prior and a burn-in period of 20,000 repetitions followed by 100,000 repetitions of sampling. As suggested by the authors, we also ran an additional analysis with uniform priors to remove any possible bias due to low 242 frequencies of alleles (Anderson \& Thompson, 2002). The results of the STRUCTURE and 
NEWHYBRIDS analyses were combined to define hybrids, following the criteria defined by Burgarella et al. (2009), to obtain the highest proportion of correctly identified hybrids. Accordingly, an individual was classified as hybrid only if satisfying two conditions: a) the sum of q-values was higher than 0.75 for all hybrid categories (F1 hybrids and backcrosses) in NEWHYBRIDS and b) it was assigned to one of the two Eptesicus species with a q-value lower than 0.90 in STRUCTURE.

\section{Approximate Bayesian Computation model-based inference of evolutionary history}

Alternative evolutionary scenarios for the two cryptic Eptesicus species were tested using the Approximate Bayesian Computation (ABC) approach implemented in DIYABC v2.1.0 (Cornuet et al., 2014). ABC analyses were carried out with the combined mtDNA and microsatellite datasets, and included all samples genotyped for the microsatellite markers. For this analysis, populations of each species were grouped into two broad geographical groups, one group at the Centre of the Iberian Peninsula, that included for each species the populations in the contact zone, and a second allopatric group at either the North (for $E$. serotinus) or the South (for E. isabellinus) of the Iberian Peninsula (see Figure 1). Separate analyses were run to determine for each species the time of population split [pre (Scenario 1.1 and 3.1) or post (Scenario 1.2 and 3.2) Last Glacial Maximum (LGM)] and changes in demographic history (Scenario 2.1 and $4.1=$ null model of no change in population size since LGM; Scenario 2.2 and 4.2= post-LGM expansion of both populations; and Scenario 2.3 and $4.3=$ post-LGM population expansion followed by more recent decline in sympatric population due to interspecific competition). Both species' dataset were then combined to compare evolutionary histories and to inspect for gene flow between species, extent and direction (Scenario 5.1= gene flow from E. serotinus to E. isabellinus sympatric populations; Scenario $5.2=$ gene flow from E. isabellinus to E. serotinus sympatric populations; and Scenario $5.3=$ no gene flow between the species). We set pre-LGM split times at $10^{4}-10^{6}$ 
268 generations ago, and post-LGM split times at $10-10^{4}$, following the assumption that 269 generation time in bats is likely to be around 2 years (e.g. Kerth et al., 2002; Flanders et al., 2009). We fixed effective population sizes $(\mathrm{Ne})$ in non-demographic analyses as equal across populations, ranging between $10^{3}$ and $10^{6}$. In the demographic history analysis $\mathrm{Ne}$ varied

272 between populations and across time, depending on the scenario (see Supporting Information

273 S2 for detailed information on scenarios and parameters).

Microsatellite loci were assumed to follow a Generalized Stepwise Mutation model (GSM) and mean mutation rate was bounded between $10^{-3}$ and $10^{-4}$ (Balloux \& LugonMoulin, 2002; Thibaut Jombart et al., 2010). The mutation rate of HVII was set at $10^{-7}-10^{-6}$ following the premise that the mutation rate of the $\mathrm{CR}$ is 10 fold faster than mtDNA genes/regions, like the Cytochrome $b$ (see Nabholz et al. 2008 for mutation rates of Cytochrome $b$ for mammals). Based on the results of $\mathrm{jModelTest}$, the mutation model was set as Kimura-2-parameters. The percentage of invariant sites was adjusted to $30 \%$ for $E$. serotinus, while the shape of the gamma distribution was adjusted to 0.5 for E. isabellinus. The majority of available summary statistics were included in all runs, but statistics specifically relevant for demographic changes, Tajima's D for the mtDNA and Mean GarzaWilliamson's M for the microsatellite datasets, were only included in the demographic history analyses. A total of $10^{6}$ simulations per scenario were tested in each analysis. The posterior probability of scenarios was estimated using a weighted polychotomous logistic regression. We checked model performance and empirically evaluated the power of the model to discriminate among scenarios and to determine confidence in scenario choice.

\section{Lyssavirus testing}

To inspect bats for Lyssavirus infection, oropharyngeal swab were collected from all captured specimens and deposited in a buffer designed for viral RNA preservation and cold 
stored until processing. In the lab, Lyssavirus RNA was searched for by a nested reverse transcription PCR targeting 260 bp of the viral nucleo-protein gene using published primers, methodology and conditions (S. Vázquez-Morón, Avellón, \& Echevarría, 2006). A positive control was run alongside samples to probe the sensitivity of the method and discard false negatives.

All sampling procedures were approved by the Ethical committee of the EBD- CSIC.

\section{RESULTS}

\section{Mitochondrial genetic diversity and structure}

The HVII fragment of the CR selected and amplified in all samples was the sequence just before the series of repeats that was 282 bp long in E. serotinus and 274 bp in E. isabellinus. Sequences were trimmed to the shortest fragment, resulting in an alignment of $277 \mathrm{bp}$ in analyses involving the two species plus outgroup. GenBank accession numbers: MH443793 to MH444139 (all-sequences alignment available in Supporting Information S3). The morphology-based identification was confirmed genetically by the tree topology obtained that showed all samples divided into two groups corresponding to the two species of bats (Supporting Information Figure S4). A total of 17 and 24 haplotypes were identified in the HVII fragment in E. serotinus and E. isabellinus, respectively. In both species, genetic diversity varied substantially among colonies regardless of their geographic location, their proximity to the edge of the distributional range, or if the colony was in contact or not with the other species (Figure 2, Table 2, Supporting Information Table S5). Overall values of genetic diversity were similar in both species. However, two colonies of $E$. isabellinus (AZN and HOR) were monomorphic with a unique haplotype shared by all their individuals (Figure 2, Table 2, Supporting Information Table S5). 

slightly lower for E. serotinus (average $\Phi_{\mathrm{ST}}=0.43 / \Phi_{\mathrm{ST}},=0.16$ ) than for E. isabellinus (average $\Phi_{\mathrm{ST}}=0.64 / \Phi_{\mathrm{ST}},=0.31$ ). Genetic differentiation between colony pairs was overall high and greater than 0.100 in all E. serotinus pairwise comparisons (Supporting Information Table S6). The lowest value of genetic differentiation was found between pairwise comparisons of E. isabellinus colonies: AZN-HOR $\left(\Phi_{\mathrm{ST}}=0.000\right)$ and SER-USO $\left(\Phi_{\mathrm{ST}}=0.029\right)$. Mantel's tests showed that IBD was not significant in either E. serotinus $(\mathrm{Z}=16.0292, \mathrm{r}=$ $0.0379, \mathrm{p}=0.57)$ or E. isabellinus $(\mathrm{Z}=94.7963, \mathrm{r}=0.5255 \mathrm{p}=0.99)$. The decomposition of the variation through the AMOVA analyses revealed that over half of the variation was found 'within populations' for E. serotinus, and under all scenarios the 'between populations' component explained less than $7 \%$ of the total variability found in the species (Supporting Information Table S7). For E. isabellinus, instead, the 'within populations' variation component was much lower $(<25 \%)$, and the 'between groups' component instead, was relatively important for all designs ( $>25 \%$ ). In summary, the AMOVAs indicated that genetic variability is more geographically structured in this species (Supporting Information Table S7). This conclusion was also supported by the haplotype networks (Figure 2). The network of E. serotinus showed no structure between groups of colonies whereas the haplotypes of $E$. isabellinus appeared in two geographically separate groups (East and North of Spain). These groups were connected by the most frequently sampled haplotype that shows a star-like topology.

\section{Nuclear genetic diversity and structure}

A total of 77 E. serotinus and 231 E. isabellinus were genotyped for the 12 selected microsatellites. Loci EF6 and EF15 were subsequently removed because they showed high frequency $(>0.05)$ of null alleles in 10 and 16 of the 19 colonies, respectively. There was no evidence of linkage disequilibrium among the remaining 10 microsatellite loci (Table 2, 
Supporting Information Table S8). Only one colony of E. serotinus (CTJ) and the colonies JAR, SER and USO of E. isabellinus showed significant deviations from HWE (Table 2, Supporting Information Table S8). All colonies had lower genetic diversity than expected under HWE, as also reflected in their positive $\mathrm{F}_{\text {IS }}$ indexes, with the exception of TRJ. The overall significant genetic structure $\left(\mathrm{F}_{\mathrm{ST}}=0.132 ; 95 \% \mathrm{CI}: 0.083-0.203\right)$ was caused by the pairwise comparisons between E. isabellinus and E. serotinus (mean: 0.281; min: 0.202, $\max =0.367)$, whereas intraspecific pairwise comparisons between colonies showed quite shallow genetic structure in both species (E. serotinus: overall $\mathrm{F}_{\mathrm{ST}}=0.047,95 \% \mathrm{CI}=0.027-$ 0.069; E. isabellinus: overall $\left.\mathrm{F}_{\mathrm{ST}}=0.011,95 \% \mathrm{CI}=0.003-0.016\right)$. The multi-species Bayesian analysis of population genetic structure clearly differentiated between E. isabellinus and $E$. serotinus and divided all genotyped individuals into two clusters $(\mathrm{K}=2)$ in agreement with the taxonomic distinction of two species (Figure 3). When STRUCTURE was run for each species separately, E. isabellinus did not show any intraspecific genetic structure $(\mathrm{K}=1)$, whereas E. serotinus individuals were divided into two clusters $(\mathrm{K}=2)$ and individuals from the CTJ, PCR and TUD colonies were mostly admixed (Figure 3B). A strong interspecific genetic structure was also observed with DAPC (Figure 3C) differentiating E. serotinus and E. isabellinus.

Results from NEWHYBRIDS and STRUCTURE identified hybrid individuals in both species, though the frequency was clearly uneven (28\% of E. serotinus versus $5 \%$ of $E$. isabellinus bats). All hybrids identified according to the most restricted criteria were found in the contact zone. The five hybrid individuals in E. isabellinus were found in three out of the five colonies that were sampled in the contact zone (BOQ: $n=3$, COR: $n=1$ and GAR: $n=1$, $15.79 \%, 5.26 \%$, and $7.14 \%$ of the sampled individuals in each colony respectively). On the other hand, the proportion of hybrids was remarkably high in the only two colonies of $E$. serotinus sampled in the zone of sympatry, CTJ ( $\mathrm{n}=7$ out of $19,36.84 \%)$ and PCR ( $\mathrm{n}=2$ out of 
$3659,15.38 \%$ ), while no hybrids were found in any of the allopatric colonies. A detailed report of 366 the proportion of hybrids within each colony is found in Supporting Information Table S9.

ABC model-based inference placed both species' population split times as post-LGM and the older population as the allopatric population (E. isabellinus: posterior probability $>0.99$, error rates $<0.0001$; E. serotinus: posterior probability $>0.99$, error $\operatorname{rates}<0.0001$ ). In the case of E. isabellinus, the central, sympatric population was colonized from the southern populations at approximately 6,250 years ago (ya) (75\% Credible Intervals: 2,000-9,800 ya), while the central E. serotinus population was colonized from the northern population at around 2,600 ya $(75 \%$ CI: $1,400-5,100$ ya). The combined model indicates that contact between the sympatric central populations of the two species has allowed the hybridization through gene flow from $E$. isabellinus to E. serotinus (posterior probability $=0.870$ ), with rates of admixture estimated at 0.252 of the E. serotinus population ( $75 \%$ CI: $0.193-0.325$; Figure 4). Interestingly, this is a very similar value to the hybridization rate found in the NEWHYBRIDS analysis. Demographic history models indicate that both populations of $E$. isabellinus have expanded more than 100 fold post-LGM, while in the case of E. serotinus the allopatric (northern) population expanded by just under 10 fold and the sympatric (central) population by nearly 100 fold. None of the populations have subsequently decreased in size following contact with their cryptic sister species (E. serotinus: posterior probability $=0.722$, error rates $=0.118 ;$ E. isabellinus: posterior probability $=0.950$, error rates $=0.086$; see Supporting Information S2 for DIYABC outputs). saliva swabs of any of the sampled bats. 
Cryptic speciation and hybridization are evolutionary processes that have contributed substantially to the origin and distribution of biodiversity. Nevertheless, the interaction between these two processes has been largely overlooked, in particularly in mammals, even though hybridization between cryptic species is expected to be relatively high (Mallet, 2005). Using genetic markers (mitochondrial and nuclear) with different modes of inheritance we show differences in the recent evolutionary histories of two cryptic bat species (E. serotinus and E. isabellinus) in Iberia, and provide strong evidence for asymmetric hybridization between sympatric populations.

Overall mitochondrial genetic diversity values were similar in both species. These values were close to those reported for E. serotinus from other parts of Europe (C Moussy et al., 2015) and slightly higher than those of the American congener, E. fuscus (Neubaum, Douglas, Douglas, \& O’Shea, 2007). Still, genetic diversity varied substantially between colonies and two allopatric colonies of E. isabellinus were completely monomorphic at the mtDNA level (AZN and HOR). The diversity values showed no differences between colonies in the contact zone (which also represents the North and South edge-of-range of the two species) and the more central populations (Figure 2), contrary to the expected pattern of reduced diversity in peripheral populations (Bridle \& Vines, 2007). In fact, colonies of $E$. isabellinus near the distribution limit were neither scarcer nor smaller than colonies at the center of the species distribution. The lack of pattern indicates that the species' edge-of-range may be recent and that diversity values may result instead from prevailing environmental conditions or the evolutionary history of each colony. For instance, the two monomorphic colonies were located in recently built concrete bridges and their lack of diversity probably reflects random fixation of alleles during recent colony formation due to founder effect. $E$. serotinus, on the other hand, seemed to be rarer in the contact zone, and despite intense search efforts, only two maternity colonies (PCR and CTJ) and a few vagrant males were found in 
413 the area. Nevertheless, these two colonies at the edge of the species range did not show lower 414 values of genetic diversity. Interestingly, the social structure of the colony does not seem to 415 determine colony diversity either because the only colony of bachelor males sampled (TUD) 416 showed similar values as the other maternity colonies. Mitochondrial and nuclear genetic differentiations confirm the species status of $E$. serotinus and E. isabellinus (Javier Juste et al., 2013), although genetic structure varied considerably between markers, as well as between species. In fact, whereas most of the variation in E. serotinus was found within colonies, E. isabellinus showed twice as much differentiation among colonies and this variation component was geographically structured with a distinction between a group of Southern (Andalusian) colonies and a group of colonies along the Northern swath in the Central Plateau that are separated by the Sierra Morena mountains (Figure 2). This pattern matches that found in bats by Juste et al. (2009), as well as in plants (Nieto Feliner, 2014) and amphibians (Martínez-Solano, 2004). Levels of differentiation between colonies are similar to levels found in other continental colonies of $E$. serotinus (C Moussy et al., 2015), and are typical of sedentary or short-distance migrating bats (Caroline Moussy et al., 2013). Differentiation among colonies was mostly high in all mtDNA pairwise comparisons, and can be associated with the strong roost fidelity of females (J Juste et al., 2009). This mtDNA structure contrasts with the results of the microsatellite dataset that, apart from supporting the specific distinction of the two bats, show a weak genetic structure, indicating male-mediated gene flow between colonies. Clustering analyses did not reveal any pattern in either of the two bats, likely due to the overall weak genetic structure (Latch, Dharmarajan, Glaubitz, \& Rhodes, 2006). The differences between mtDNA and nDNA markers stress the different roles played by females and males in relation to the genetic structuring of the populations. Dispersing males are responsible for gene flow between populations, while the philopatric behavior of females results in strong genetic 
structure at the mtDNA level. These sex-biased differences are considered typical for most bat species (Altringham, 2011), and have been described in several species, including Rhinolophus ferrumequinum (Flanders et al., 2009), Myotis myotis (Ruedi et al., 2008), Miniopterus schreibersii (Ramos Pereira, Salgueiro, Rodrigues, Coelho, \& Palmeirim, 2009) and Myotis escalerai, in the Iberian Peninsula (Razgour et al. 2015). The colonies JAR, SER and USO of E. isabellinus and CTJ of E. serotinus were not in Hardy-Weinberg equilibrium, suggesting population sub-structuring or deviation from random mating. These colonies were all located at the edge of the distribution areas, which may explain the deficit of heterozygotes combined with a potential Wahlund effect due to possible sampling of different family groups within colonies (Hansen, Nielsen, \& Mensberg, 1997).

The best supported recent evolutionary history scenarios based on the $\mathrm{ABC}$ analysis using the joint mDNA and nDNA dataset suggest that both bats expanded in Iberia after the LGM from their respective refuges: E. serotinus expanded southwards and E. isabellinus northwards. According to the results, the refuge in the case of E. isabellinus was probably located in the southwestern corner of the Peninsula as suggested by Juste et al. (2009). There is no information on the refuge of E. serotinus, but the lack of genetic structure, even across Europe (Moussy et al., 2015, Troupin et al., 2017), suggests a rapid expansion of E. serotinus as new suitable habitats opened in Europe. In Iberia, ABC inference indicates a slightly older expansion for E. isabellinus, which would explain its relatively deeper geographic structure based on the mtDNA marker. Interestingly, neither of the two bats seems to have experienced population declines either during the expansion or after the contact. The expansions could have been reciprocally limited by the presence of the other species due to competitive exclusion, eventually resulting in the present parapatric distribution along an East-West axis in the center of the Peninsula. Alternatively, the sharp environmental changes in the contact zone from the forested mountain habitats to more xeric open lands may have played a role in 
463 defining the current distribution edges, given the important differences in the environmental optima of the two species according to their species distribution models (Santos et al., 2014). The contact zone between the two species seems to be much wider in Portugal (Rebelo, 2013), where the transition between Atlantic and Mediterranean environments is smoother. To fully understand the current dynamics and to make reasonable predictions about shifts in the species' limits, more information is needed on both patterns and processes occurring within and adjacent to the contact zone (Harrison, 1986).

Our empirical evidence revealed no mitochondrial introgression between the two species because all the colonies showed unambiguous haplotypes belonging to either one species or the other. Accordingly, colonies in the contact zone did not show higher mtDNA diversity, as would have been expected had they incorporated alien haplotypes. Interestingly, mitochondrial introgression with the co-generic E. nilssonii was detected in Western populations of E. serotinus (Artyushin et al., 2009) and probably associated to its post-glacial expansion. However, the nuclear markers identified in our study an ongoing male-mediated asymmetric hybridization from E. isabellinus to E. serotinus (28\% in E. serotinus and $5 \%$ in E. isabellinus) in the contact zone. Asymmetric hybridization has been also recently reported in the species complex of Myotis myotis and M. byithii, two bat species roosting in mixed maternity colonies (Afonso, Goydadin, Giraudoux, \& Farny, 2017). Asymmetry in the genetic exchange is relatively common (Barton \& Hewitt, 1985) and can be promoted by different life history traits (e.g. sex differences in body size, mating strategies, dispersal behavior etc.). In this case, however, the two cryptic bats are highly similar in their morphology, echolocation characteristics and ecology (J. Juste et al., 2017). Alternatively, asymmetric introgression could arise from post-mating barriers, such as sex-biased sterility and fitness differences (Barton \& Hewitt, 1985), or could simply be the result of differences in abundance, whereby the rarer species is more likely to mate with the other species simply because hetero-specifics 
are more common in the area. Hybridization also enables the establishment of new populations, as species shift their distribution range and overlap with competing species through the acquisition of local genetic adaptations (Hovick and Whitney, 2014). The negative effects of species competition may be ameliorated by the combined effects of demographic mechanisms (e.g. colonization/extinction of bat colonies) and severe Allee effects without implying any new adaptive change in hybrids (Mesgaran et al., 2016). The proportion of hybrids found in one of the colonies of E. serotinus (PCR) is almost double the number of hybrids found in the other colony (CTJ). These differences could indicate clinal variation, though more colonies need to be sampled to validate this hypothesis. The presence of hybrids only in the narrow contact zone points to a recent genetic exchange rather than past overlap in species distributions as suggested for other bats (Mao et al., 2010).

Hybridization is often related to particular social behaviors. In the case of the bat Myotis alcathoe it has been linked to the particular swarming behavior of bats that gather to mate in multi-specific ensembles in places like cave entrances (Bogdanowicz et al., 2012). For other bats, like the Asian horseshoe bats, hybrids were associated with opportunistic winter mating with torpid females (Mao et al., 2010). For the European serotine, as for the American E. fuscus, it is still unknown when mating takes place (Maarten J. Vonhof, Strobeck, \& Fenton, 2008). Detailed data on mating behavior are needed to fully understand the possible relationship between hybridization and specific aspects of their social life.

EBLV-1 is the zoonotic rabies virus most frequently detected in bats in Europe, and both Eptesicus species are considered its main reservoirs (Sonia Vázquez-Morón et al., 2008). Lyssavirus-positive bats were not found in this study, in line with previous results for Eptesicus isabellinus showing viral RNA presence in only $2.8 \%$ of more than a thousand bats tested (Sonia Vázquez-Morón et al., 2008). E. serotinus and E. isabellinus host distinct and characteristic EBLV1 virus strains, each with a different phylogenetic history (Sonia 
513 Vázquez-Morón et al., 2011). A recent study has reported the first detection of an EBLV-1 of 514 the strain considered typical of E. isabellinus in an E. serotinus bat from North-Eastern Spain 515 (Patricia Mingo-Casas et al., 2018). The sequence of this virus is close to a known southern sequence of the virus, which suggests a recent transmission from E. isabellinus to $E$. serotinus, in agreement with the direction of the asymmetrical hybridization described in our study. The process of viral transmission across bat species is not well understood, but most probably requires close contact between the bats (Echevarría, Avellón, Juste, Vera, \& Ibáñez, 2001; Sonia Vázquez-Morón et al., 2008). Whether the transmission of the virus strain was in fact promoted by the asymmetric hybridization and whether this host exchange in the EBLV-1 strains is widespread are questions in need of further investigation.

\section{Conclusions}

The herein described hybridization between E. serotinus and E. isabellinus is a new example to add to the surprisingly short list of hybridizing bat species (reviewed in Bogdanowicz et al., 2012). Nevertheless, the extent of hybridization reported in the literature might be an underestimation because, like in our case study, hybrids are frequently impossible to distinguish morphologically from the parental species (Mallet, 2005). Interestingly, out of the less than twenty hybridization events (including introgression) reported for bats, the majority involves pairs of cryptic but not necessarily sister species, from the large Pteropus fruit bats (Webb \& Tidemann, 1995) to the tiny European Pipistrellus (Sztencel-Jabłonka \& Bogdanowicz, 2012). This pattern is pointing to an association of hybridization with other evolutionary processes linked to cryptic species, such as parallelism or stasis (Struck et al., 2017), although with exceptions such as the cryptic species complex of European Plecotus that maintain totally isolated their genetic pools even in sympatry (Andriollo et al., 2018). This particular case could result from the high level of differentiation between these lineages 
538 incompatibilities or genetic breakdown when their genomes are assembled together, making a

539 successful hybridization between them probably more attainable, especially in secondary

540 contact zones. Nevertheless, the relationships between hybridization and level of

541 differentiation still need more studies to be properly understood.

542

543

544

545

546

547

548

549

550

551

552

553

554

555

556

557

\section{ACKNOWLEDGEMENTS}

We thank all the people that helped in collecting the bat samples in the field over several years, particularly Xosé Pardevila, Roberto H. Hermida, Jesús Nogueras, Godfried Schreur, Joserra Ailhartza, Ignazio Garín and all the volunteer students that helped in the sampling. Begoña Adrados for her help and support in the lab work. Logistical support was provided by the Laboratorio de Ecología Molecular, Estación Biológica de Doñana, CSIC (LEM-EBD). Prof. Kent Rylander from TTU, Texas, improved the manuscript with comments and suggestions. We acknowledge the autonomous governments of Galicia, Basque Country, Castilla y León, Castilla -La Mancha, Extremadura and Andalucía for their support and for providing permits. This work was funded by CSIC (project number: 200430E330), the Spanish Ministry of Science and Education (SAF2006-12784-C02-02) and the Spanish Ministry of Environment (PPNN181/2010) and the Spanish Severo Ochoa Programme (SEV-2012-0262). O. Razgour was funded through a Natural Environment Research Council (NERC) Independent Research Fellowship (NE/M018660/1). 


\section{RESUMEN}

559 Los procesos de especiación críptica e hibridación son determinantes para el origen y 560 mantenimiento de la biodiversidad, así como para nuestra capacidad de conocerla y estimarla.

561 En este trabajo estudiamos colonias en alopatría y simpatría de dos especies crípticas de 562 murciélagos (Eptesicus serotinus y E. isabellinus) con distribución parapátrica en la península

563 ibérica. Se sabe que estas especies suponen el principal reservorio para los virus de la rabia 564 más comunes en murciélagos en Europa: Lyssavirus tipo 1 de los murciélagos europeos 565 (EBLV-1). Utilizamos ADN mitocondrial y microsatélites para confirmar la taxonomía de 566 ambas especies y para mostrar que en E. isabellinus existe una mayor estructura genética correlacionada con la distribución geográfica que la encontrada en E. serotinus. Datamos una expansión de rango rápida en ambas especies tras el ultimo máximo glacial hasta que alcanzaron su actual área de distribución, utilizando para ello métodos basados en la computación de aproximación bayesiana $(\mathrm{ABC})$. Estos análisis también confirman diferencias

571 interespecíficas en la diversidad genética y estructura, lo que sugiere una expansión hacia el

572 Norte de E. Isabellinus anterior a la de la especie hermana. No encontramos introgresión del 573 ADN mitocondrial entre especies, aunque el análisis de los microsatélites identificaron una hibridación asimétrica actual de E. isabellinus hacia E. serotinus en la zona de contacto (28\% 575 de híbridos en E. serotinus y $5 \%$ en E. isabellinus). A pesar de que ninguno de los 576 especímenes analizados portaban ARN de Lyssavirus, la hibridación asimétrica detectada en 577 este estudio justifica el potencial de transmisión del EBLV-1 de E. isabellinus hacia E. 578 serotinus. 
580

581

582

583

584

585

586

587

588

589

590

591

592

593

594

595

596

597

598

599

600

601

\section{REFERENCES}

Abbott, R., Albach, D., Ansell, S., Arntzen, J. W., Baird, S. J. E., Bierne, N., ... Zinner, D. (2013). Hybridization and speciation. Journal of Evolutionary Biology, 26(2), 229-246. https://doi.org/10.1111/j.1420-9101.2012.02599.x

Afonso, E., Goydadin, A.-C., Giraudoux, P., \& Farny, G. (2017). Investigating Hybridization between the Two Sibling Bat Species Myotis myotis and M. blythii from Guano in a Natural Mixed Maternity Colony. PloS One, 12(2), e0170534. https://doi.org/10.1371/journal.pone.0170534

Allendorf, F. W., Leary, R. F., Spruell, P., \& Wenburg, J. K. (2001). The problems with hybrids: setting conservation guidelines. Trends in Ecology \& Evolution, 16(11), 613622. https://doi.org/10.1016/S0169-5347(01)02290-X

Altringham, J. D. (2011). Bats: from Evolution to Conservation. Oxford Biology.

Anderson, E. C., \& Thompson, E. a. (2002). A model-based method for identifying species hybrids using multilocus data. Genetics, 160(3), 1217-1229. https://doi.org/test statistics; hybrids

Artyushin, I. V., Bannikova, A. A., Lebedev, V. S., \& Kruskop, S. V. (2009). Mitochondrial DNA relationships among North Palaearctic Eptesicus (Vespertilionidae, Chiroptera) and past hybridization between Common Serotine and Northern Bat. Zootaxa, 2262(1), 40-52. https://doi.org/10.11646/zootaxa.2262.1.2

Balloux, F., \& Lugon-Moulin, N. (2002). The estimation of population differentiation with microsatellite markers. Molecular Ecology, 11(2), 155-165. Retrieved from http://www.ncbi.nlm.nih.gov/pubmed/11856418 
602 Bandelt, H. J., Forster, P., \& Röhl, a. (1999). Median-joining networks for inferring 603 intraspecific phylogenies. Molecular Biology and Evolution, 16(1), 37-48. Retrieved 604 from http://www.ncbi.nlm.nih.gov/pubmed/10331250

605

606

607

608

609

610

611

612

613

614

615

616

617

618

619

620

621

622

623

624

Barton, N. H., \& Hewitt, G. M. (1985). Analysis of Hybrid Zones. Annual Review of Ecology and Systematics, 16(1), 113-148. https://doi.org/10.1146/annurev.es.16.110185.000553

Battey, C. J., \& Klicka, J. (2017). Cryptic speciation and gene flow in a migratory songbird Species Complex: Insights from the Red-Eyed Vireo ( Vireo olivaceus ). Molecular Phylogenetics and Evolution, 113, 67-75. https://doi.org/10.1016/j.ympev.2017.05.006

Beaumont, M. A., Zhang, W., \& Balding, D. J. (2002). Approximate Bayesian computation in population genetics. Genetics, 162(4), 2025-2035. Retrieved from http://www.pubmedcentral.nih.gov/articlerender.fcgi?artid=1462356\&tool=pmcentrez\&r endertype $=$ abstract

Belkhir K, Borsa, P, Chikhi, L., Raufaste, N., \& Bonhomme, F. (2004). GENETIX 4.05, logiciel sous Windows TM pour la génétique des populations. Montpellier (France): Belkhir K., Borsa P., Chikhi L., Raufaste N. \& Bonhomme F. 1996-2004 GENETIX 4.05, logiciel sous Windows TM pour la génétique des populations. Laboratoire Génome, Populations, Interactions, CNRS UMR 5171, Université de Montpellier II.

Berthier, P., Excoffier, L., \& Ruedi, M. (2006). Recurrent replacement of mtDNA and cryptic hybridization between two sibling bat species Myotis myotis and Myotis blythii. Proceedings of the Royal Society B: Biological Sciences, 273(October), 3101-3109. https://doi.org/10.1098/rspb.2006.3680

Bickford, D., Lohman, D. J., Sodhi, N. S., Ng, P. K. L. L., Meier, R., Winker, K., ... Das, I. (2007). Cryptic species as a window on diversity and conservation. Trends in Ecology 

and Evolution, 22(3), 148-155. https://doi.org/10.1016/j.tree.2006.11.004

626

627

628

629

630

631

632

633

634

635

636

637

638

639

640

641

642

643

644

645

646

Bogdanowicz, W., Piksa, K., \& Tereba, A. (2012). Hybridization Hotspots at Bat Swarming Sites. PLoS ONE, 7(12). https://doi.org/10.1371/journal.pone.0053334

Bohling, J. H., Adams, J. R., \& Waits, L. P. (2013). Evaluating the ability of Bayesian clustering methods to detect hybridization and introgression using an empirical red wolf data set. Molecular Ecology, 22(1), 74-86. https://doi.org/10.1111/mec.12109

Bridle, J. R., \& Vines, T. H. (2007). Limits to evolution at range margins: when and why does adaptation fail? Trends in Ecology \& Evolution, 22(3), 140-147. https://doi.org/10.1016/j.tree.2006.11.002

Burgarella, C., Lorenzo, Z., Jabbour-Zahab, R., Lumaret, R., Guichoux, E., Petit, R. J., ... Gil, L. (2009). Detection of hybrids in nature: application to oaks (Quercus suber and Q. ilex). Heredity, 102(5), 442-452. https://doi.org/10.1038/hdy.2009.8

Burland, T. M., Barratt, E. M., \& Racey, P. A. (1998). Isolation and characterization of microsatellite loci in the brown long-eared bat, Plecotus auritus, and cross species ampliccation within the family Vespertilionidae. Molecular Ecology, 7, 136-138.

Canestrelli, D., Porretta, D., Lowe, W. H., Bisconti, R., Carere, C., Nascetti, G., ... al., et. (2016). The Tangled Evolutionary Legacies of Range Expansion and Hybridization. Trends in Ecology \& Evolution, 31(9), 677-688. https://doi.org/10.1016/j.tree.2016.06.010

Carstens, B. C., \& Richards, C. L. (2007). Integrating coalescent and ecological niche modeling in comparative phylogeography. Evolution; International Journal of Organic Evolution, 61(6), 1439-1454. https://doi.org/10.1111/j.1558-5646.2007.00117.x 
647 Casas, I., Powell, L., Klapper, P. E., \& Cleator, G. M. (1995). New method for the extraction 648 of viral RNA and DNA from cerebrospinal fluid for use in the polymerase chain reaction 649 650 assay. Journal of Virological Methods, 53(1), 25-36. https://doi.org/10.1016/01660934(94)00173-E

651

652

653

654

655

656

657

658

659

660

661

662

663

664

665

666

667

668

669

Castella, V., \& Ruedi, M. (2000). Characterization of highly variable microsatellite loci in the bat Myotis myotis (Chiroptera: Vespertilionidae). Molecular Ecology, 9(7), 1000-1002. https://doi.org/10.1046/j.1365-294x.2000.00939-6.x

Chapuis, M.-P., \& Estoup, A. (2007). Microsatellite null alleles and estimation of population differentiation. Molecular Biology and Evolution, 24(3), 621-631. https://doi.org/10.1093/molbev/ms1191

Cornuet, J.-M., Pudlo, P., Veyssier, J., Dehne-Garcia, A., Gautier, M., Leblois, R., ... Estoup, A. (2014). DIYABC v2.0: a software to make approximate Bayesian computation inferences about population history using single nucleotide polymorphism, DNA sequence and microsatellite data. Bioinformatics, 30(8), 1187-1189. https://doi.org/10.1093/bioinformatics/btt763

Crochet, P. a. (2000). Genetic structure of avian populations--allozymes revisited. Molecular Ecology, 9(10), 1463-1469. Retrieved from http://www.ncbi.nlm.nih.gov/pubmed/11050542

Currat, M., Ruedi, M., Petit, R. J., \& Excoffier, L. (2008). The hidden side of invasions: Massive introgression by local genes. Evolution, 62(8), 1908-1920. https://doi.org/10.1111/j.1558-5646.2008.00413.x

de Vienne, D. M., Refrégier, G., López-Villavicencio, M., Tellier, A., Hood, M. E., \& Giraud, T. (2013). Cospeciation vs host-shift speciation: methods for testing, evidence from 
670

671

672

673

674

675

676

677

678

679

680

681

682

683

684

685

686

687

688

689

690

691

692

natural associations and relation to coevolution. New Phytologist, 198(2), 347-385. https://doi.org/10.1111/nph.12150

Dietz, C., Nill, D., \& Helversen, O. . (2009). Bats of Britain, Europe and Northwest Africa. London, UK: A \& C Black, London.

Doña, J., Sweet, A. D., Johnson, K. P., Serrano, D., Mironov, S., \& Jovani, R. (2017). Cophylogenetic analyses reveal extensive host-shift speciation in a highly specialized and host-specific symbiont system. Molecular Phylogenetics and Evolution, 115, 190196. https://doi.org/10.1016/j.ympev.2017.08.005

Dool, S. E., Puechmaille, S. J., Dietz, C., Juste, J., Ibáñez, C., Hulva, P., ... Teeling, E. C. (2013). Phylogeography and postglacial recolonization of Europe by Rhinolophus hipposideros: Evidence from multiple genetic markers. Molecular Ecology, 22(15), 4055-4070. https://doi.org/10.1111/mec.12373

Earl, D. A., \& vonHoldt, B. M. (2011). STRUCTURE HARVESTER: a website and program for visualizing STRUCTURE output and implementing the Evanno method. Conservation Genetics Resources, 4(2), 359-361. https://doi.org/10.1007/s12686-0119548-7

Echevarría, J. E., Avellón, A., Juste, J., Vera, M., \& Ibáñez, C. (2001). Screening of active lyssavirus infection in wild bat populations by viral RNA detection on oropharyngeal swabs. Journal of Clinical Microbiology, 39(10), 3678-3683. https://doi.org/10.1128/JCM.39.10.3678-3683.2001

Evanno, G., Regnaut, S., \& Goudet, J. (2005). Detecting the number of clusters of individuals using the software STRUCTURE: a simulation study. Molecular Ecology, 14(8), 26112620. https://doi.org/10.1111/j.1365-294X.2005.02553.x 
693 Excoffier, L., \& Lischer, H. E. L. (2010). Arlequin suite ver 3.5: A new series of programs to 694 perform population genetics analyses under Linux and Windows. Molecular Ecology Resources, 10(3), 564-567. https://doi.org/10.1111/j.1755-0998.2010.02847.x

696

697

698

699

700

701

702

703

704

705

706

707

708

709

710

711

712

713

714

715

Excoffier, L., Smouse, P. E., \& Quattro, J. M. (1992). Analysis of molecular variance inferred from metric distances among DNA haplotypes: application to human mitochondrial DNA restriction data. Genetics, 131(2), 479-491. Retrieved from http://www.ncbi.nlm.nih.gov/pubmed/1644282

Falush, D., Stephens, M., \& Pritchard, J. K. (2007). Inference of population structure using multilocus genotype data: dominant markers and null alleles. Molecular Ecology Notes, 7(4), 574-578. https://doi.org/10.1111/j.1471-8286.2007.01758.x

Fitzpatrick, B. M. (2012). Estimating ancestry and heterozygosity of hybrids using molecular markers. BMC Evolutionary Biology, 12, 131. https://doi.org/10.1186/1471-2148-12-131

Fitzpatrick, B. M., Fordyce, J. A., Niemiller, M. L., \& Reynolds, R. G. (2012). What can DNA tell us about biological invasions? Biological Invasions, 14(2), 245-253. https://doi.org/10.1007/s10530-011-0064-1

Flanders, J. O. N., Jones, G., Benda, P., Dietz, C., Zhang, S., Li, G., ... Rossiter, S. J. (2009). Phylogeography of the greater horseshoe bat, Rhinolophus ferrumequinum: contrasting results from mitochondrial and microsatellite data. Molecular Ecology, 18(2), 306-318. https://doi.org/10.1111/j.1365-294X.2008.04021.x

Frankel, O. H. (1974). Genetic conservation: our evolutionary responsibility. Genetics, 78(1), 53-65. Retrieved from http://www.pubmedcentral.nih.gov/articlerender.fcgi?artid=1213213\&tool=pmcentrez\&r endertype $=$ abstract 
Goudet, J. (1995). FSTAT (Version 1.2): A Computer Program to Calculate F-Statistics. $J$. Hered., 86(6), 485-486. Retrieved from http://jhered.oxfordjournals.org/content/86/6/485.citation

Hansen, M. M., Nielsen, E. E., \& Mensberg, K.-L. D. (1997). The problem of sampling families rather than populations: relatedness among individuals in samples of juvenile brown trout Salmo trutta L. Molecular Ecology, 6(5), 469-474. https://doi.org/10.1046/j.1365-294X.1997.t01-1-00202.x

Harrison, R. G. (1986). Pattern and process in a narrow hybrid zone. Heredity, 56(3), 337349. https://doi.org/10.1038/hdy.1986.55

Hewitt, G. M. (2001). Speciation, hybrid zones and phylogeography - or seeing genes in space and time. Molecular Ecology, 10(3), 537-549. Retrieved from http://www.ncbi.nlm.nih.gov/pubmed/11298967

Hoffmann, F. G., Owen, J. G., \& Baker, R. J. (2003). mtDNA perspective of chromosomal diversification and hybridization in Peters' tent-making bat (Uroderma bilobatum: Phyllostomidae). Molecular Ecology, 12(11), 2981-2993. Retrieved from http://www.ncbi.nlm.nih.gov/pubmed/14629379

Holsinger, K. E., \& Weir, B. S. (2009). Genetics in geographically structured populations: defining, estimating and interpreting F(ST). Nature Reviews. Genetics, 10(9), 639-650. https://doi.org/10.1038/nrg2611

Ibáñez, C., García-Mudarra, J. L., Ruedi, M., Stadelmann, B., \& Juste, J. (2006). The Iberian contribution to cryptic diversity in European bats. Acta Chiropterologica, 8(2), 277-297. https://doi.org/10.3161/1733-5329(2006)8[277:TICTCD]2.0.CO;2

Jakobsson, M., \& Rosenberg, N. a. (2007). CLUMPP: a cluster matching and permutation 

program for dealing with label switching and multimodality in analysis of population structure. Bioinformatics (Oxford, England), 23(14), 1801-1806. https://doi.org/10.1093/bioinformatics/btm233

Jensen, J. L., Bohonak, A. J., \& Kelley, S. T. (2005). Isolation by distance, web service. BMC Genetics, 6, 13. https://doi.org/10.1186/1471-2156-6-13

Jombart, T. (2008). adegenet: a R package for the multivariate analysis of genetic markers. Bioinformatics, 24(11), 1403-1405. https://doi.org/10.1093/bioinformatics/btn129

Jombart, T., Devillard, S., Balloux, F., Falush, D., Stephens, M., Pritchard, J., ... Nei, M. (2010). Discriminant analysis of principal components: a new method for the analysis of genetically structured populations. BMC Genetics, 11(1), 94 . https://doi.org/10.1186/1471-2156-11-94

Juste, J., Benda, P., Garcia-Mudarra, J. L., \& Ibáñez, C. (2013). Phylogeny and systematics of Old World serotine bats (genus Eptesicus, Vespertilionidae, Chiroptera): An integrative approach. Zoologica Scripta, 42(5), 441-457. https://doi.org/10.1111/zsc.12020

Juste, J., Bilgin, R., Muñoz, J., \& Ibáñez, C. (2009). Mitochondrial DNA signatures at different spatial scales: From the effects of the Straits of Gibraltar to population structure in the meridional serotine bat (Eptesicus isabellinus). Heredity, 103(2), 178-187. https://doi.org/10.1038/hdy.2009.47

Juste, J., Ibáñez, C., de Paz, O., Martinez-Alos, S., Vázquez-Hernandez, A., Nogueras, J., ... Echevarria, J. (2017). Los murciélagos en los Parques Nacionales de Monfragüe y Cabañeros: diversidad, especies crípticas de murciélago hortelano y presencia viral. In L. Ramirez \& B. Asensio (Eds.), Investigación en Red. Colección "Naturaleza y Parques Nacionales” Monografías del Ministerio de Medio Ambiente (pp. 293-306). OAPN. 
Kerth, G., Safi, K., \& König, B. (2002). Mean colony relatedness is a poor predictor of colony structure and female philopatry in the communally breeding Bechstein's bat ( Myotis bechsteinii ). Behavioral Ecology and Sociobiology, 52(3), 203-210. https://doi.org/10.1007/s00265-002-0499-6

Koopman, K. F. (1993). Order Chiroptera. In D. E. Wilson \& M. Reeder (Eds.), Mammal species of the world: a taxonomic and geographic reference (Second Edi, pp. 137-241). Washington: Smithsonian Institution Press.

Latch, E. K., Dharmarajan, G., Glaubitz, J. C., \& Rhodes, O. E. (2006). Relative performance of Bayesian clustering software for inferring population substructure and individual assignment at low levels of population differentiation. Conservation Genetics, 7(2), 295302. https://doi.org/10.1007/s10592-005-9098-1

Librado, P., \& Rozas, J. (2009). DnaSP v5: a software for comprehensive analysis of DNA polymorphism data. Bioinformatics (Oxford, England), 25(11), 1451-1452. https://doi.org/10.1093/bioinformatics/btp187

Maguilla, E., \& Escudero, M. (2016). Cryptic Species Due to Hybridization: A Combined Approach to Describe a New Species (Carex: Cyperaceae). PLOS ONE, 11(12), e0166949. https://doi.org/10.1371/journal.pone.0166949

Mallet, J. (2005, May). Hybridization as an invasion of the genome. Trends in Ecology and Evolution. Elsevier. https://doi.org/10.1016/j.tree.2005.02.010

Mallet, J. (2007). Hybrid speciation. Nature, 446(7133), 279-283. https://doi.org/10.1038/nature05706

Mallet, J., Besansky, N., \& Hahn, M. W. (2016). How reticulated are species? BioEssays, 38(2), 140-149. https://doi.org/10.1002/bies.201500149 
Mao, X. G., Zhu, G. J., Zhang, S., \& Rossiter, S. J. (2010). Pleistocene climatic cycling drives intra-specific diversification in the intermediate horseshoe bat (Rhinolophus affinis) in Southern China. Molecular Ecology, 19(13), 2754-2769. https://doi.org/10.1111/j.1365294X.2010.04704.X

Mao, X., Zhang, J., Zhang, S., \& Rossiter, S. J. (2010). Historical male-mediated introgression in horseshoe bats revealed by multilocus DNA sequence data. Molecular Ecology, 19(7), 1352-1366. https://doi.org/10.1111/j.1365-294X.2010.04560.x

Martínez-Solano, I. (2004). Phylogeography of Iberian Discoglossus (Anura: Discoglossidae). Journal of Zoological Systematics and Evolutionary Research, 42(4), 298-305. https://doi.org/10.1111/j.1439-0469.2004.00257.x

Martinsson, S., \& Erséus, C. (2017). Cryptic speciation and limited hybridization within Lumbricus earthworms (Clitellata: Lumbricidae). Molecular Phylogenetics and Evolution, 106, 18-27. https://doi.org/10.1016/j.ympev.2016.09.011

Mesgaran, M. B., Lewis, M. A., Ades, P. K., Donohue, K., Ohadi, S., Li, C., \& Cousens, R. D. (2016). Hybridization can facilitate species invasions, even without enhancing local adaptation. Proceedings of the National Academy of Sciences, 113(36), 10210-10214. https://doi.org/10.1073/pnas.1605626113

Mingo-Casas, P., Sandonís, V., Obón, E., Berciano, J. M., Vázquez-Morón, S., Juste, J., \& Echevarría, J. E. (2018). First cases of European bat lyssavirus type 1 in Iberian serotine bats: Implications for the molecular epidemiology of bat rabies in Europe. PLoS Neglected Tropical Diseases, 12(4), e0006290. https://doi.org/10.1371/journal.pntd.0006290 

(2017). Rabies in Spain. A Peculiarity in Eurasia. Annals Virology Research, 3(2), 1030.

Mitchell, S. M., Muehlbauer, L. K., \& Freedberg, S. (2016). Nuclear introgression without mitochondrial introgression in two turtle species exhibiting sex-specific trophic differentiation. Ecology and Evolution, 6(10), 3280-3288. https://doi.org/10.1002/ece3.2087

Moussy, C., Atterby, H., Griffiths, A. G. F. F., Allnutt, T. R., Mathews, F., Smith, G. C., ... Hosken, D. J. (2015). Population genetic structure of serotine bats (Eptesicus serotinus) across Europe and implications for the potential spread of bat rabies (European bat lyssavirus EBLV-1). Heredity, 115(1), 83-92. https://doi.org/10.1038/hdy.2015.20

Moussy, C., Hosken, D. J., Mathews, F., Smith, G. C., Aegerter, J. N., \& Bearhop, S. (2013, July 1). Migration and dispersal patterns of bats and their influence on genetic structure. Mammal Review. Wiley/Blackwell (10.1111). https://doi.org/10.1111/j.13652907.2012.00218.x

Nesi, N., Nakouné, E., Cruaud, C., \& Hassanin, A. (2011). DNA barcoding of African fruit bats (Mammalia, Pteropodidae). The mitochondrial genome does not provide a reliable discrimination between Epomophorus gambianus and Micropteropus pusillus. Comptes Rendus Biologies, 334(7), 544-554. https://doi.org/10.1016/j.crvi.2011.05.003

Neubaum, M. A., Douglas, M. R., Douglas, M. E., \& O’Shea, T. J. (2007). Molecular Ecology of the Big Brown Bat (Eptesicus Fuscus): Genetic and Natural History Variation in a Hybrid Zone. Journal of Mammalogy, 88(5), 1230. https://doi.org/10.1644/06-MAMM-A-228R1.1

Nieto Feliner, G. (2014, October 10). Patterns and processes in plant phylogeography in the Mediterranean Basin. A review. Perspectives in Plant Ecology, Evolution and 
Petri, B., Pääbo, S., Von Haeseler, A., \& Tautz, D. (1997). Paternity assessment and population subdivision in a natural population of the larger mouse-eared bat Myotis myotis. Molecular Ecology, 6(3), 235-242. Retrieved from http://www.ncbi.nlm.nih.gov/pubmed/9076978

Pfenninger, M., \& Schwenk, K. (2007). Cryptic animal species are homogeneously distributed among taxa and biogeographical regions. BMC Evolutionary Biology. https://doi.org/10.1186/1471-2148-7-121

Ramos Pereira, M. J., Salgueiro, P., Rodrigues, L., Coelho, M. M., \& Palmeirim, J. M. (2009). Population structure of a cave-dwelling bat, Miniopterus schreibersii: does it reflect history and social organization? The Journal of Heredity, 100(5), 533-544. https://doi.org/10.1093/jhered/esp032

Randi, E. (2008). Detecting hybridization between wild species and their domesticated relatives. Molecular Ecology, 17(1), 285-293. https://doi.org/10.1111/j.1365294X.2007.03417.x

Rebelo, H. (2013). Eptesicus serotinus/Eptesicus isabellinus. In Rainho (Ed.), Atlas dos morcegos de Portugal continental (pp. 47-50). Lisbon: Inst. Cons. Nat. Flor.

Richards, C. L., Carstens, B. C., \& Lacey Knowles, L. (2007). Distribution modelling and statistical phylogeography: an integrative framework for generating and testing alternative biogeographical hypotheses. Journal of Biogeography, 34(11), 1833-1845. https://doi.org/10.1111/j.1365-2699.2007.01814.x

Rousset, F. (2008). genepop'007: a complete re-implementation of the genepop software for Windows and Linux. Molecular Ecology Resources, 8(1), 103-106. 
https://doi.org/10.1111/j.1471-8286.2007.01931.x

Ruedi, M., Walter, S., Fischer, M. C., Scaravelli, D., Excoffier, L., \& Heckel, G. (2008). Italy as a major Ice Age refuge area for the bat Myotis myotis (Chiroptera: Vespertilionidae) in Europe. Molecular Ecology, 17(7), 1801-1814. https://doi.org/10.1111/j.1365294X.2008.03702.x

Sambrook, J., Fritsch, E. F., Maniatis, T., Harbor, U. S. A., \& Slatkin, M. (1989). Molecular cloning.: A Laboratory Manual. Cold Spring Harbor, USA.: Cold Spring Harbor Laboratory Press.

Santos, H., Juste, J., Ibáñez, C., Palmeirim, J. M., Godinho, R., Amorim, F., ... Rebelo, H. (2014). Influences of ecology and biogeography on shaping the distributions of cryptic species: three bat tales in Iberia. Biological Journal of the Linnean Society, 112(1), 150162. https://doi.org/10.1111/bij.12247

Schuelke, M. (2000). An economic method for the fluorescent labeling of PCR fragments A poor man 's approach to genotyping for research and high-throughput diagnostics ., 18(February), 1-2.

Seehausen, O., Takimoto, G., Roy, D., \& Jokela, J. (2008). Speciation reversal and biodiversity dynamics with hybridization in changing environments. Molecular Ecology, 17(1), 30-44. https://doi.org/10.1111/j.1365-294X.2007.03529.x

Simmons, N. B. (2005). Order Chiroptera. In D. E. Wilson \& M. Reeder (Eds.), Mammal Species of the World: A Taxonomic and Geographic Reference (pp. 312-529). Baltimore: The Johns Hopkins University Press.

Soltis, P. S., \& Soltis, D. E. (2009). The Role of Hybridization in Plant Speciation. Annual Review of Plant Biology, 60(1), 561-588. 

https://doi.org/10.1146/annurev.arplant.043008.092039

Struck, T. H., Feder, J. L., Bendiksby, M., Birkeland, S., Cerca, J., Gusarov, V. I., ... Dimitrov, D. (2017, March). Finding Evolutionary Processes Hidden in Cryptic Species. Trends in Ecology and Evolution, pp. 153-163. https://doi.org/10.1016/j.tree.2017.11.007

Swofford, D. L., Waddell, P. J., Huelsenbeck, J. P., Foster, P. G., Lewis, P. O., \& Rogers, J. S. (2001). Bias in phylogenetic estimation and its relevance to the choice between parsimony and likelihood methods. Systematic Biology, 50(4), 525-539. Retrieved from http://www.ncbi.nlm.nih.gov/pubmed/12116651

Sztencel-Jabłonka, A., \& Bogdanowicz, W. (2012). Population genetics study of common (Pipistrellus pipistrellus) and soprano (Pipistrellus pygmaeus) pipistrelle bats from central Europe suggests interspecific hybridization. Canadian Journal of Zoology, 90(May), 1251-1260. https://doi.org/10.1139/z2012-092

Vähä, J.-P., \& Primmer, C. R. (2006). Efficiency of model-based Bayesian methods for detecting hybrid individuals under different hybridization scenarios and with different numbers of loci. Molecular Ecology, 15(1), 63-72. https://doi.org/10.1111/j.1365294X.2005.02773.X

Vázquez-Morón, S., Avellón, A., \& Echevarría, J. E. (2006). RT-PCR for detection of all seven genotypes of Lyssavirus genus. Journal of Virological Methods, 135(2), 281-287. https://doi.org/10.1016/j.jviromet.2006.03.008

Vázquez-Morón, S., Juste, J., Ibáñez, C., Berciano, J. M., \& Echevarría, J. E. (2011). Phylogeny of european bat lyssavirus 1 in eptesicus isabellinus bats, Spain. Emerging Infectious Diseases, 17(3), 520-523. https://doi.org/10.3201/eid1703100894 
900

901

902

903

904

905

906

907

908

909

910

911

912

913

914

915

916

917

918

919

920

921

Vázquez-Morón, S., Juste, J., Ibáñez, C., Ruiz-Villamor, E., Avellón, A., Vera, M., \& Echevarría, J. E. Endemic circulation of European bat lyssavirus type 1 in serotine bats, Spain., 14 Emerging infectious diseases $§(2008)$. Centers for Disease Control and Prevention. https://doi.org/10.3201/eid1408.080068

Vonhof, M. J., Davis, C. S., Strobeck, C., \& Fenton, M. B. (2001). Characterization of microsatellite loci in Spix's disk-winged bats (Thyroptera tricolor). Molecular Ecology Notes, 1(1-2), 73-75. https://doi.org/10.1046/j.1471-8278.2001.00030.x

Vonhof, M. J., Strobeck, C., \& Fenton, M. B. (2008). Genetic Variation and Population Structure in Big Brown Bats (Eptesicus fuscus ): Is Female Dispersal Important? Journal of Mammalogy, 89(6), 1411-1420. https://doi.org/10.1644/08-MAMM-S-062.1

Webb, N., \& Tidemann, C. (1995). Hybridisation between black (Pteropus alecto) and greyheaded (P. poliocephalus) flying-foxes (Megachiroptera: Pteropodidae). Australian Mammalogy, 18, 19-26.

Wilkinson, G. S., \& Chapman, A. M. (1991). Length and sequence variation in evening bat D-loop mtDNA. Genetics, 128(3), 607-617. Retrieved from http://www.ncbi.nlm.nih.gov/pubmed/1874418

Wilmer, J. W., Moritz, C., Hall, L., \& Toop, J. (1994). Extreme population structuring in the threatened ghost bat, Macroderma gigas: evidence from mitochondrial DNA. Proceedings. Biological Sciences, 257(1349), 193-198. https://doi.org/10.1098/rspb.1994.0115

Worthington-Wilmer, J., \& Barratt, E. (1996). A Non-Lethal Method of Tissue Sampling for Genetic Studies of Chiropterans. Bat Research News, 37(1), 1-4. 
923

924

925

926

927

928

929

930

931

932

933

934

935

936

937

\section{Titles and legends to figures.}

Figure 1. Sampled colonies of Eptesicus serotinus (triangles and red) and E. isabellinus (circles and blue) in the Iberian Peninsula. See Table 1 for acronyms. The contact zone is marked with a shaded ellipse and the colonies within it have light colors.

Figure 2. Left: Histograms showing the distribution of mtDNA nucleotide diversity $(\pi)$ by colonies for 1a) Eptesicus serotinus and 1b) E. isabellinus. Histograms of populations included in the contact zone are shown in light red (E. serotinus) and light blue (E. isabellinus), otherwise in full color. Right: Median-Joining network between HVII haplotypes of the two species of bats: 2a) Eptesicus serotinus and 2b) E. isabellinus. Circles are proportional to the number of individuals presenting each haplotype. Similarly, light red and light blue circles correspond to the contact zone. The little red dots are reconstructed or missing haplotypes and each red bar in the connecting lines represent a change. Dashed lines in 2b) divide geographic regions.

Figure 3. Population structure of Eptesicus serotinus and E. isabellinus in Spain. Bar plots showing the inferred group assignment of all bats sampled from E. serotinus and $E$. isabellinus based on the STRUCTURE analysis and grouped by colony for all individuals (A) and considering only E.serotinus individuals according to their mtDNA signature (B). Discriminant Analysis of Principal Components (DAPC) based on 10 microsatellites (C). The two main groups correspond to Eptesicus serotinus (right) and E. isabellinus (left).

Figure 4. Patterns of post-Last Glacial Maximum range expansion by Eptesicus serotinus (red triangles) and E. isabellinus (blue squares) in the Iberian Peninsula based on ABC inference. The allopatric populations of each species are marked with circles or polygons and the sympatric populations with ellipses. Direction of range expansion is marked with straight 
arrows, indicating the median estimated time of expansion. Gene flow between species is marked with a curved arrow, indicating hybridization rates.

\section{List of Supporting Information}

- Supporting Information S1. PCR amplification conditions for mitochondrial and microsatellite markers.

- Supporting Information S2. Analyses and Results of DIYABC.

- Supporting Information S3. Nexus file containing all sequences of the section of the hyper-variable II region (HVII) of the mitochondrial control region (CR) used in this study (available online).

- Supporting Information Figure S4. Phlylogenetic reconstruction based on HVII of Eptesicus isabellinus and E. serotinus using a Maximum Parsimony (MP) criterion.

- Supporting Information Table S5. Mitochondrial diversity in Eptesicus serotinus and E. isabellinus.

- Supporting Information Table S6. Pairwise genetic distances between colonies of $E$. serotinus and E. isabellinus.

- Supporting Information Table S7. Two and four grouping designs of Molecular analyses of Variance (AMOVA).

- Supporting Information Table S8. Test of Hardy-Weinberg Equilibrium and genetic diversity found across species, colonies and loci for Eptesicus serotinus and E. isabellinus.

- Supporting Information Table S9. Number of individuals identified as pure Eptesicus isabellinus, pure E. serotinus, hybrids or unclassified by NewHybrids, Structure and the combined criterion following Burgarella et al. (2009). 
972 TABLES

973 Table 1 - Colonies of Eptesicus serotinus and E. isabellinus sampled in this study. See Figure 9741 for the spatial layout of locations.

975

981

982

983

984

985

E. isabellinus Allopatry

ALC Alcalá del Río (Sevilla)

37.5185

$-5.9748$

986

987

988

989

990

991

992

993

994

995

996

997

998

AZN Aznalcollar (Sevilla)

37.5340

$-6.3017$

ORG Órgiva (Granada)

36.8719

$-3.4728$

POS Posadas (Córdoba)

37.7968

$-5.1052$

TRJ Puente Trajano (Sevilla)

37.0326

$-5.9272$

HOR Horcajo de los Montes

39.2905

$-4.5516$

(Ciudad Real)

USO Puente Río Uso (Toledo)

39.7341

$-5.0570$

BOQ Boquerón (Ciudad Real)

39.4928

$-4.5422$

Contact Zone

COR Corrinche (Cáceres)

39.7754

$-5.7137$

GAR Garrovillas (Cáceres)

39.7543

$-6.4375$

JAR Jaraicejo (Cáceres)

39.7517

$-5.8490$

SER Serradilla (Cáceres)

39.7916

$-6.1320$

TOR Torrejón el Rubio (Cáceres)

39.8298

$-6.0351$

999 
1001

1002

1003

1004

1005

Table 2 - Mitochondrial [number of haplotypes $(\boldsymbol{h})$, haplotype diversity $(\boldsymbol{H d})$, nucleotide diversity $(\boldsymbol{\pi})$, number of polymorphic sites $(\boldsymbol{S})$ ] and nuclear diversity [observed $(\boldsymbol{H o})$ and expected ( $\boldsymbol{H e}$ ) heterozygosity] across all loci and by colony.

\begin{tabular}{|ccccccccccl|}
\hline \multicolumn{10}{c|}{ Eptesicus serotinus } \\
\hline Colony & $\boldsymbol{N}$ & $\boldsymbol{h}$ & $\boldsymbol{H} \boldsymbol{d}$ & $\boldsymbol{\pi}$ & $\boldsymbol{S}$ & $\boldsymbol{N}$ & $\boldsymbol{H e}$ & $\boldsymbol{H o}$ & Overall & $\boldsymbol{F}$ is \\
\hline CHA & 19 & 8 & 0.795 & 0.008 & 12 & 11 & 0.4676 & 0.4128 & 0.3355 & 0.123 \\
TUD & 15 & 5 & 0.781 & 0.004 & 4 & 14 & 0.5439 & 0.4859 & 0.1676 & 0.111 \\
PCR & 19 & 4 & 0.45 & 0.007 & 12 & 13 & 0.6956 & 0.6352 & 0.9143 & 0.097 \\
CTJ & 20 & 3 & 0.647 & 0.007 & 5 & 19 & 0.6164 & 0.3355 & 0.0295 & 0.02 \\
CAN & 20 & 3 & 0.468 & 0.002 & 2 & 17 & 0.4092 & 0.4094 & 0.6164 & 0 \\
UGA & 14 & 2 & 0.363 & 0.001 & 1 & 3 & 0.53 & 0.5167 & 1 & 0.05 \\
\hline Total & 107 & 17 & 0.894 & 0.008 & 16 & $\mathbf{7 7}$ & 0.628 & 0.57 & 0.5105 & 0.052 \\
\hline
\end{tabular}

Eptesicus isabellinus

\begin{tabular}{|lllllllllll|}
\hline \multicolumn{7}{c|}{ Mitochondrial } & \multicolumn{4}{c|}{ Nuclear } \\
\hline Colony & $\boldsymbol{N}$ & $\boldsymbol{h}$ & $\boldsymbol{H} \boldsymbol{d}$ & $\boldsymbol{\pi}$ & $\boldsymbol{S}$ & $\boldsymbol{N}$ & $\boldsymbol{H e}$ & $\boldsymbol{H o}$ & Overall & Fis \\
\hline JAR & 17 & 5 & 0.735 & 0.006 & 6 & 16 & 0.7161 & 0.6397 & 0.0035 & 0.111 \\
AZN & 18 & 1 & 0 & 0 & 0 & 19 & 0.7012 & 0.6473 & 0.1547 & 0.084 \\
ORG & 24 & 3 & 0.598 & 0.005 & 4 & 24 & 0.6846 & 0.6367 & 0.1746 & 0.07 \\
ALC & 20 & 4 & 0.5 & 0.003 & 4 & 18 & 0.7038 & 0.6547 & 0.0705 & 0.071 \\
GAR & 14 & 2 & 0.264 & 0.003 & 3 & 14 & 0.7206 & 0.6892 & 0.7209 & 0.046 \\
COR & 19 & 2 & 0.456 & 0.008 & 5 & 19 & 0.695 & 0.6918 & 0.8417 & 0.005 \\
HOR & 20 & 1 & 0 & 0 & 0 & 20 & 0.6989 & 0.6887 & 0.1778 & 0 \\
POS & 11 & 6 & 0.727 & 0.006 & 6 & 5 & 0.6934 & 0.67 & 0.9682 & 0.036 \\
USO & 20 & 3 & 0.353 & 0.005 & 11 & 19 & 0.6711 & 0.6499 & 0.013 & 0.032 \\
SER & 22 & 4 & 0.571 & 0.003 & 3 & 22 & 0.6822 & 0.6082 & 0.036 & 0.111 \\
BOQ & 19 & 5 & 0.713 & 0.005 & 9 & 19 & 0.6883 & 0.681 & 0.0547 & 0.011 \\
TOR & 17 & 2 & 0.382 & 0.001 & 1 & 18 & 0.6874 & 0.6603 & 0.6647 & 0.041 \\
TRJ & 19 & 2 & 0.491 & 0.002 & 1 & 18 & 0.6886 & 0.6918 & 0.2941 & -0.005 \\
\hline Total & 240 & 24 & 0.840 & 0.013 & 27 & 231 & 0.70 & 0.66 & 0.3211 & 0.049 \\
\hline
\end{tabular}




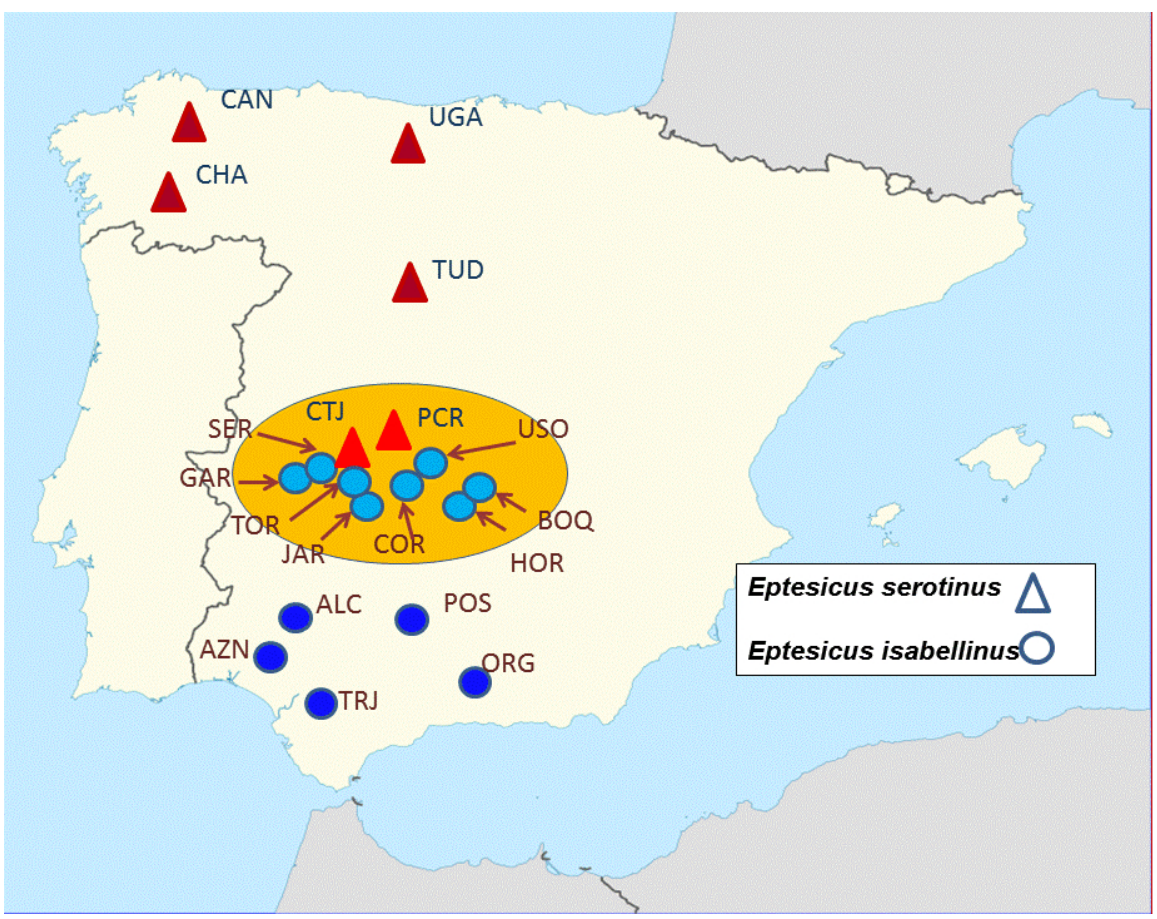

Sampled colonies of Eptesicus serotinus (triangles and red) and E. isabellinus (circles and blue) in the Iberian Peninsula. See Table 1 for acronyms. The contact zone is marked with a shaded ellipse and the colonies within it have light colors. 


\section{Eptesicus serotinus}

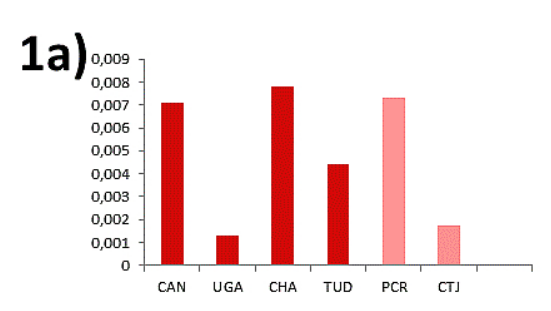

Eptesicus isabellinus

\section{1b)}

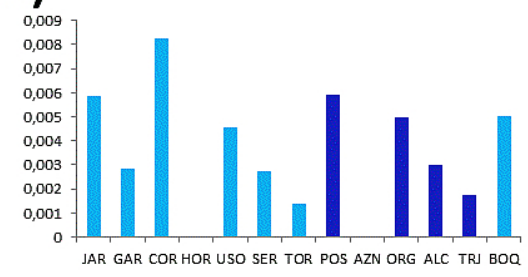

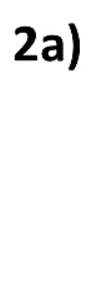

2b)
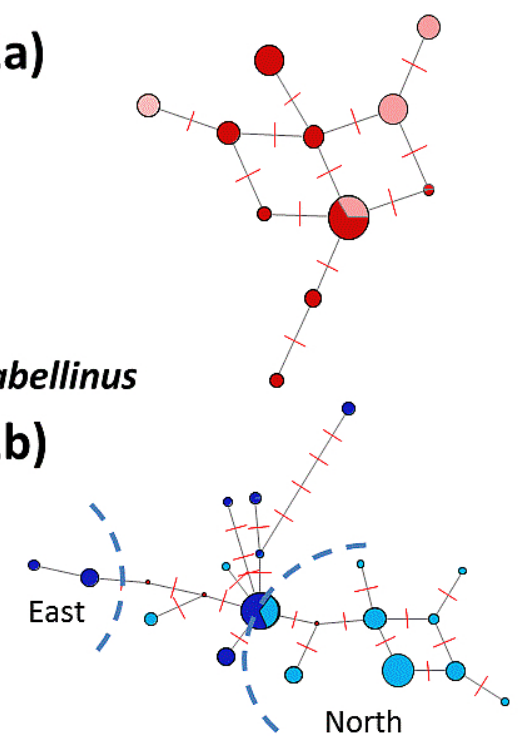

Left: Histograms showing the distribution of mtDNA nucleotide diversity ( $\Pi$ ) by colonies for 1a) Eptesicus serotinus and $1 \mathrm{~b}$ ) E. isabellinus. Histograms of populations included in the contact zone are shown in light red (E. serotinus) and light blue (E. isabellinus), otherwise in full color. Right: Median-Joining network between HVII haplotypes of the two species of bats: $2 a$ ) Eptesicus serotinus and 2b) E. isabellinus. Circles are proportional to the number of individuals presenting each haplotype. Similarly, light red and light blue circles correspond to the contact zone. The little red dots are reconstructed or missing haplotypes and each red bar in the connecting lines represent a change. Dashed lines in $2 b$ ) divide geographic regions. 

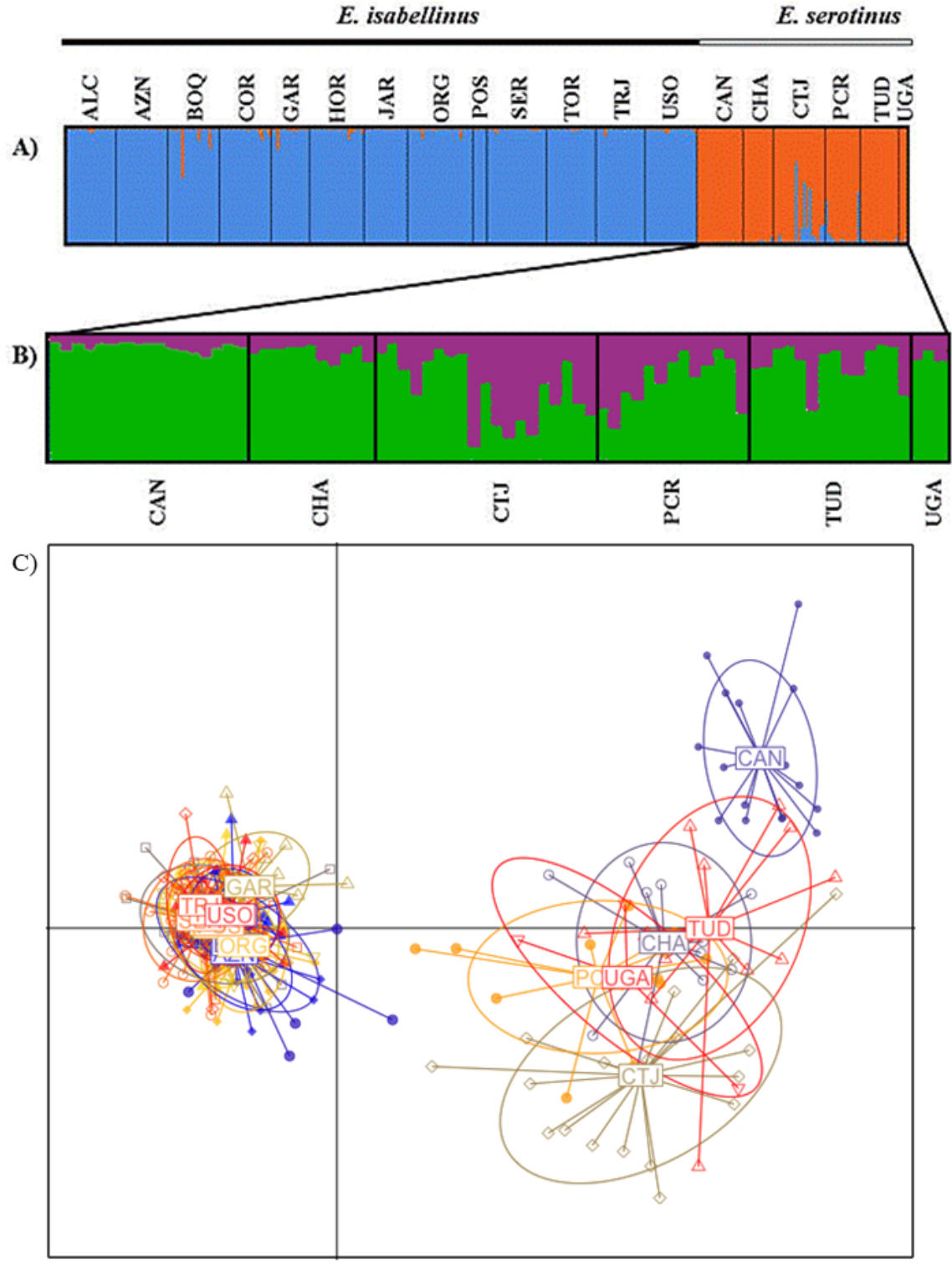

Population structure of Eptesicus serotinus and E. isabellinus in Spain. Bar plots showing the inferred group assignment of all bats sampled from E. serotinus and E. isabellinus based on the STRUCTURE analysis and grouped by colony for all individuals $(A)$ and considering only E.serotinus individuals according to their mtDNA signature (B). Discriminant Analysis of Principal Components (DAPC) based on 10 microsatellites (C). The two main groups correspond to Eptesicus serotinus (right) and E. isabellinus (left). 


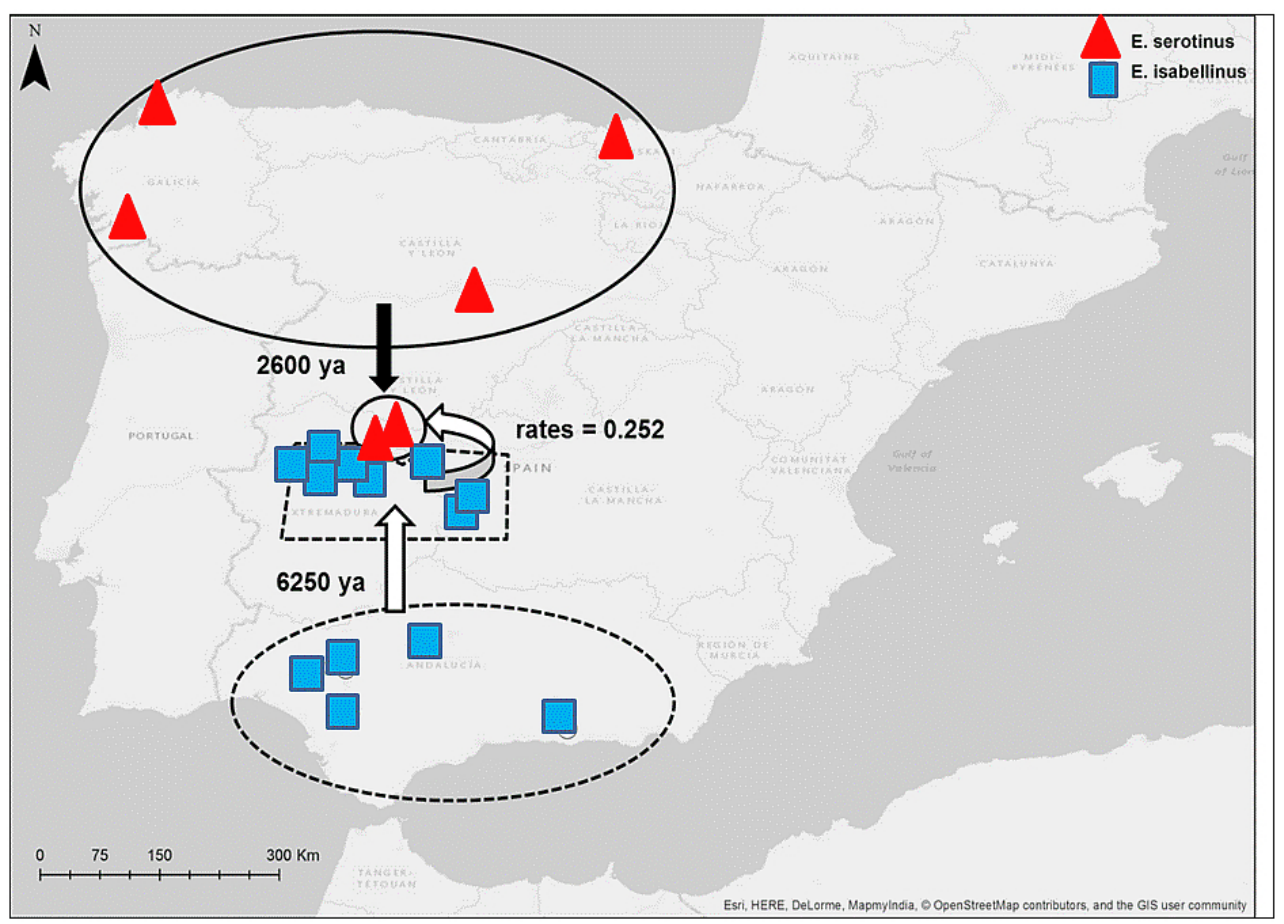

Patterns of post-Last Glacial Maximum range expansion by Eptesicus serotinus (red triangles) and E. isabellinus (blue squares) in the Iberian Peninsula based on ABC inference. The allopatric populations of each species are marked with circles or polygons and the sympatric populations with ellipses. Direction of range expansion is marked with straight arrows, indicating the median estimated time of expansion. Gene flow between species is marked with a curved arrow, indicating hybridization rates. 